Article

\title{
Design and Development of Continuous Passive Motion (CPM) for Fingers and Wrist Grounded-Exoskeleton Rehabilitation System
}

\author{
Husam Almusawi ${ }^{1, *(D)}$ and Géza Husi ${ }^{2}$ (D) \\ 1 Faculty of Informatics, University of Debrecen, Kassai útca 26, 4028 Debrecen, Hungary \\ 2 Department of Mechatronics, Faculty of Engineering, University of Debrecen, Ótemető útca 2-4, \\ 4028 Debrecen, Hungary; husigeza@eng.unideb.hu \\ * Correspondence: husam@eng.unideb.hu; Tel.: +36-70-213-9368
}

Citation: Almusawi, H.; Husi, G. Design and Development of Continuous Passive Motion (CPM) for Fingers and Wrist GroundedExoskeleton Rehabilitation System Appl. Sci. 2021, 11, 815. https:// doi.org/10.3390/app11020815

Received: 27 October 2020 Accepted: 12 January 2021 Published: 16 January 2021

Publisher's Note: MDPI stays neutral with regard to jurisdictional clai$\mathrm{ms}$ in published maps and institutional affiliations.

Copyright: (C) 2021 by the authors. Licensee MDPI, Basel, Switzerland. This article is an open access article distributed under the terms and conditions of the Creative Commons Attribution (CC BY) license (https:// creativecommons.org/licenses/by/ $4.0 /)$.

\begin{abstract}
Impairments of fingers, wrist, and hand forearm result in significant hand movement deficiencies and daily task performance. Most of the existing rehabilitation assistive robots mainly focus on either the wrist training or fingers, and they are limiting the natural motion; many mechanical parts associated with the patient's arms, heavy and expensive. This paper presented the design and development of a new, cost-efficient Finger and wrist rehabilitation mechatronics system (FWRMS) suitable for either hand right or left. The proposed machine aimed to present a solution to guide individuals with severe difficulties in their everyday routines for people suffering from a stroke or other motor diseases by actuating seven joints motions and providing them repeatable Continuous Passive Motion (CPM). FWRMS approach uses a combination of; grounded-exoskeleton structure to provide the desired displacement to the hand's four fingers flexion/extension (F/E) driven by an indirect feed drive mechanism by adopting a leading screw and nut transmission; and an endeffector structure to provide angular velocity to the wrist flexion/ extension (F/E), wrist radial/ulnar deviation $(\mathrm{R} / \mathrm{U})$, and forearm supination/pronation $(\mathrm{S} / \mathrm{P})$ driven by a rotational motion mechanism. We employed a single dual-sided actuator to power both mechanisms. Additionally, this article presents the implementation of a portable embedded controller. Moreover, this paper addressed preliminary experimental testing and evaluation process. The conducted test results of the FWRMS robot achieved the required design characteristics and executed the motion needed for the continuous passive motion rehabilitation and provide stable trajectories guidance by following the natural range of motion (ROM) and a functional workspace of the targeted joints comfortably for all trainable movements by FWRMS.
\end{abstract}

Keywords: hand recovery; rehabilitation robotics; stroke; indirect drive system; grounded-exoskeleton; continuous passive motion (CPM); wrist rehabilitation; assistive technologies

\section{Introduction}

A stroke around the world is the second reason for death and the third most significant source of inability [1]. Among all 15 million, about 5 million die, $66 \%$ of these deaths occur in case of individuals above the age of 70 years [2]. A significant number of individuals with motor impairments are among the stroke survivors. In fact, in the initial motion, all post-stroke survivors and patients with hereditary conditions may experience handfunction impairments [3]. The hand is one of the foremost vital limbs of humans; it consists of five fingers and a wrist, therefore advancing robotics technologies designed to restore sensory-motor function [4,5]. In general, to manage the stroke's debilitating impact on patients' upper limbs, particular finger and wrist exercises may help. The wrist is the proximate range of the carpal bones shaped by the radius and the articular disks [6]. Rehabilitation care recommendations suggest that patients receive care for brain injury as soon as possible [7]. The significant advancement in conventional recovery approaches has 
contributed to assistive robotics. Rehabilitation robotic has progressed and increased the human quality of life significantly. Increasing emphasis was given to technical advances in robotics during refurbishment training [8,9].

According to state of the art in the literature [10-12], rehabilitation robots listed into two types: (1) portable devices support daily living activities ADLs. This group of systems is wearable devices; they also can be fixed onto tables; they are configured to direct patients' manipulators to execute simple ADL at home (e.g., holding things, grasping, and using a phone). However, in the early stage of stroke, portability is not crucial since the victims cannot perform normal ADLs. Nevertheless, challenges must be considered with these systems; the number of required actuators increases with joints numbers to be trained, which obviously leads to an increase in the essential energy supply, weight, complexity, and cost. (2) the second group of assistive-robotic devices calls therapeutic systems, more significant than the ADLs supporting devices. Due to their complexity and size, they are often suitable only for therapeutic clinics and too expensive even for some local clinics.

Considering the mechanical characteristics, it binds to the target limb and passes the movements into the affected limbs through the mechanical structure. Exoskeleton-based structure and end-effector systems are the most common structures for assisting robots. The comparison between the two approaches is that exoskeleton-based is an external framework that reflects the body frame of the target limb's skeleton; this approach can be grounded and ungrounded, allowing an independent joints motion with a different number of degrees freedom DOFs. However, because the human hand is a complex structure, exoskeletonbased devices need to follow this complexity; a typical exoskeleton-based device called Kawasaki [13] supports 18 DOF and uses 22 Servo motors. Another exoskeleton-based system is called RUPERT IV [14], with 5 DOFs. Another device called Haptic Knob, Lambercy [15] uses 2 DC brushed motors and provide 2 DOF. The end-effector-based devices, a more straightforward and practical approach, in which the targeted limb interacts with the end-point device with less mechanical integrations. Typical end-effector development; My Scrivener, Obslap Reseach, LLC; Palsbo [16], this system provides 3 DOFs.

Regarding the gesture assistance mode developments, the rehabilitation devices can be divided into interactive systems (e.g., haptic devices), passive mode, and active assistive motion (AAM). At this point, AAM and passive assistive motion systems are the most reported rehabilitation system. As a comparison, passive assistive systems can direct the patient's affected limb movement. These devices are only suited for stroke victims who can lift their extremities; therefore, these systems are often not necessarily required to be driven by an actuator [11,17]. Therefore, passive devices typically lighter in weight and require less energy than active devices [10]. On the other hand, the AAM devices equipped with the actuation unit, one of the widely utilized actuators in neurorehabilitation robotic systems, is electric motors [18]. AAM devices are used to move patient limbs actively; they are best used when they cannot perform simple ADLs movements. However, some active devices consider passive because the end-user effort is not required; practically, the end-user remains inert while the device provides an active motion to the integrated joint. These systems help guide and guarantee that the patient's limb follows the planned workspace trajectory by providing continuous passive motion (CPM) [10].

CPM machines are one of the most frequently cited methods of treatment supported by the developed therapy exoskeletons. Passive mode is helpful to avoid early recovery of muscular contractures. Thus, the CPM machine became more particularly helpful in the initial phase in contrast to existing exoskeletons in literature. A significant number have been indicated to improve the range of motion, displacement, and grabbing capacity of the wrist or fingers neurorehabilitation robotics based on CPMs have been designed. Moreover, they are the most popular technologies in the industry to improve motor-sensory disability for upper-limbs. In the market commercial, CPM-based development can be found [19-24]. The most highly developed existing commercial products are Amadeo, Tyromotion [19], which is based on an end-effector design that uses an electric motor to train five fingers for either hand. Another popular CPM machine developed by Sammons 
Preston Kinetec Masters [20], this system targets the fingers and wrist. Another commercially available Hand Mentor TM, Kinematic Muscles [21], is a wearable orthosis that uses one pneumatic actuator, targeting the wrist and four fingers. In addition, there are inventions for rehabilitation, available from research laboratories, publishing, and studies, in general targeting upper extremities and more specifically for finger grabs and for the wrist, which is not available on the market. AMES, Cordo [25] is a stationary system that supports one DOF, both $[16,25]$ use electric actuator and train both fingers and wrist. Another Stationary system called HWARD, Takahashi [26] supports 3 DOF and uses three Pneumatic actuators. While Hasegawa [27] is a grasp assistance device that uses 11 DC motors and supports 11 DOF. A recently published robot-looks called EULRR [28] uses two commercial manipulators, each manipulator's hand 7 DOF.

This paper presents a new design and development of a cost-efficient Fingers and Wrist Rehabilitation Mechatronic System (FWRMS). Concerning the mechanical structure, the proposed FWRMS combines a grounded exoskeleton and end-effector structures to provide repeatable a continuous passive motion for either hand left or right. The proposed system performs four essential movements of the hand which illustrated in Figure 1, the hand movement, including one fingers flexion/ Extension (F/E); two wrist movements flexion/ Extension (F/E), and Wrist Radial/ulnar (R/U), deviation; forearm pronation/supination $(\mathrm{P} / \mathrm{S})$. Furthermore, this paper also introduces a mechanical construction and transmitting system that has managed to imitate the intended joints' movements safely and comfortably in the desired trajectories. We have also proposed a portable interactive controller in this article, which allows the first user to choose the desired therapy and therapy parameters via the developed control menu.

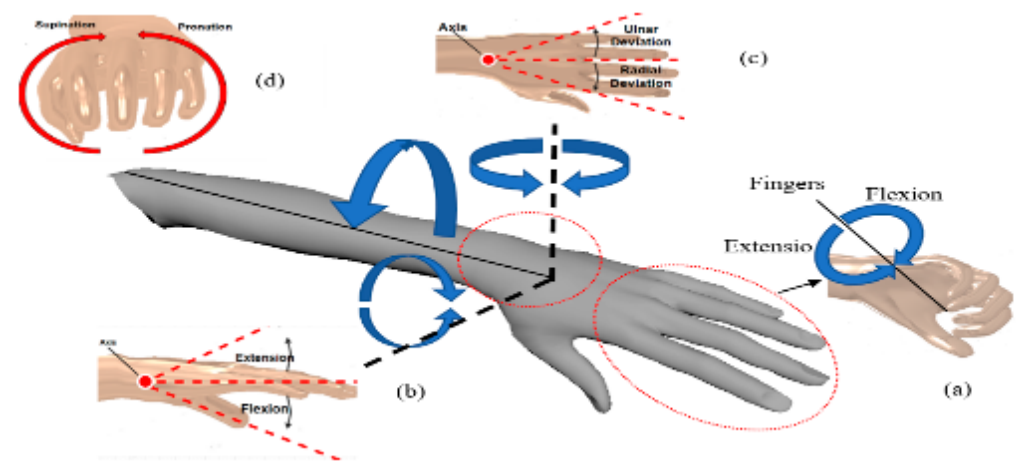

Figure 1. Overview of Fingers and Wrist Rehabilitation Mechatronic System (FWRMS) targeted movements; (a) Fingers flexion/extension; (b) Wrist flexion/extension; (c) Wrist Radial/ulnar deviation; (d) Forearm pronation/supination.

The most recent related studies in the literature, which were carried out from the literature by universities, research institutes, and studies, is concentrating on the design and development of robotics focused on upper limb assistive-robot rehabilitation systems. This section addresses some of the latest advances in the upper limb's design listed in Table 1.

Table 1. Recent elated work.

\begin{tabular}{|c|c|c|c|c|c|c|}
\hline System & $\begin{array}{l}\text { No. of Actuated } \\
\text { Movements }\end{array}$ & Training Mode & Transmission Schematic & Type of Actuator & $\begin{array}{c}\text { Mechanical } \\
\text { Structure Type }\end{array}$ & $\begin{array}{c}\text { Supported } \\
\text { Movements }\end{array}$ \\
\hline [29] & 2 & Passive & parallel mechanism & $2 *$ Servo motors & Exoskeleton & $\begin{array}{l}\text { Elbow }(\mathrm{F} / \mathrm{E}) \text { and } \\
\text { shoulder }(\mathrm{F} / \mathrm{E})\end{array}$ \\
\hline$[30]$ & 1 & Passive and active & $\begin{array}{l}\text { SPRM) with the } \\
\text { parallel mechanism }\end{array}$ & DC motor & Exoskeleton & 1 finger \\
\hline [31] & 2 & Passive and active & parallel mechanism & $2^{*}$ pneumatic actuator & End-effector & Wrist (F/E, R/U) \\
\hline [32] & 6 & CPM & rope + toothed belt & $\begin{array}{c}\text { DC motors } \\
\text { Harmonic motors }\end{array}$ & $\begin{array}{l}\text { End-effector and } \\
\text { exoskeleton }\end{array}$ & $\begin{array}{l}\text { shoulder }(\mathrm{F} / \mathrm{E}, \mathrm{I} / \mathrm{E} \text {, } \\
\mathrm{A} / \mathrm{A}) \text {, elbow }(\mathrm{F} / \mathrm{E} \text {, } \\
\mathrm{I} / \mathrm{E}) \text {; wrist }(\mathrm{E} / \mathrm{E})\end{array}$ \\
\hline [33] & 1 & Active and Passive & $\begin{array}{l}\text { Cable-driven and } \\
\text { differential rotation }\end{array}$ & PMS & exoskeleton & 1 finger $(F / E)$ \\
\hline Our FWRMS & 7 & CPM & $\begin{array}{l}\text { Indirect screw } \\
\text { nut mechanism } \\
\text { and rotational }\end{array}$ & $\begin{array}{c}1^{*} \text { Electrical Stepper } \\
\text { motor }\end{array}$ & $\begin{array}{l}\text { End-effector and } \\
\text { grounded- } \\
\text { exoskeleton }\end{array}$ & $\begin{array}{c}4 \text { Fingers }(\mathrm{F} / \mathrm{E}) \text {, } \\
\text { Wrist }(\mathrm{F} / \mathrm{E}, \mathrm{R} / \mathrm{U}) \\
\text { Forearm }(\mathrm{S} / \mathrm{P})\end{array}$ \\
\hline
\end{tabular}


In [29], the authors developed a 3D printed, wearable exoskeleton configuration based on a hybrid control system that incorporates impedance and admittance controls to define the workspace trajectory, then corrects these trajectories using electromyographic (EMG) feedback signals with two degrees of freedom, targeting the upper limb to provide elbow and shoulder joint flexion and expansion gestures.

In [30], the authors designed a wearable exoskeleton mechatronics system based on active and passive control approaches for single-finger rehabilitation. The proposed device is operated by a field-programmable gate array (FPGA) and controlled through an Android smartphone application. They employed an asymmetric pinion and rack system (SPRM), which is driven through a parallel mechanism. The developed approach is a portable mechatronics system that utilizes a DC motor. The authors used a rearmounted module placed on the patient's forearm, which connected a Bowden cable's hand exoskeleton design.

In [31], the authors developed a parallel wrist rehabilitation robot (PWRR), suitable mostly for patients suffering hypertonia, stroke, or wrist injuries. The proposed approach is based on an end-effector structure that performs constant rehabilitation training for the wrist joints, consisting of two rotational DOFs for wrist F/E and R/U movements. Two pneumatic actuators power the proposed PWRR to transfer the movement to the wrist $\mathrm{R} / \mathrm{U}$ and $\mathrm{F} / \mathrm{E}$ joints, respectively.

Authors in [32], developed a heavy stationary end-effector robot performing in total six DOFs: dividing as (1), three DOF of the shoulder joint with different: $(\mathrm{F} / \mathrm{E})$, internal/external rotation (I/E), abduction/adduction (A/A); (2), one DOF of the elbow joint: (F/E); one DOFs: (I/E); one DOF of the wrist joint: $(\mathrm{F} / \mathrm{E})$. The proposed end-effector system with a tension mechanism based on cable-driven modular parallel joint driven by a toothed belt, the transmission mechanism used a rear-mount to transmit motion for the end joints, derived by DC Servo motors and harmonic motors. The authors used an external computer-controlled machine to perform continuous passive rehabilitation.

In [33], the authors develop a single finger exoskeleton robot that can provide active and passive rehabilitation. The proposed system is driven by an antagonistic two pneumatic muscles (PMs); the transmission mechanism is based on cable transmission and differential rotation, which drives a diseased rotation to mechanical wheels which linked all the finger joints proximal (1) interphalanx; (PIP), (2) middle interphalanx (MIP); (3), and distal interphalanx (DIP). An external computer is used to control the proposed robot.

Compared to the current state of the art. A set of assistive-robots rehabilitation systems has been developed, as already summarized above. However, relatively few orthoses are configured to train the fingers and wrist joints in the same design. Currently, most of the available related rehabilitation robotic in literature targets either upper arm and forearm joints (e.g., elbow, shoulder, and some including wrist joints), or just the finger joints, since the fingers have different and complex structures and mechanisms. Therefore, it should be noted that there are still some challenges in designing a single device that can train the fingers and the wrist joints together at the same design [16,20,21,25]. However, most of the available devices are too expensive, complicated, heavy structured, and too many mechanical parts linked to the patients' arms can be unconformable to both therapists and patients. In addition, certain devices are a static platform or intended for some specific applications, specific hand and joint, like fingers joints or just the wrist joints. Furthermore, many existing devices control over an external PC without embedded control implementation. Therefore, compared to the current works in literature, the FWRMS developed in this paper contributes. Technically, FWRMS adopts a combination of grounded-exoskeleton structure driven by an indirect feed drive mechanism and an end-effector structure mechanism driven by a rotational motion mechanism. Both mechanisms are powered by a single dual-sided actuator, significantly reducing the cost, overall structure complexity, noise, and weight. We have implemented an embedded software and embedded hardware without needing an external PC from a controlling perspective. It was designed to a portable control unit to enable the first user through developed software menu to control the range 
of motion (ROM), speed, and the repetition times [17] generated by the device towards the patient's hand depending on the functionality of the finger mobility and wrist. Generally, the developed exoskeleton fingertips and wrist attachments are removable, replaceable, and sterilizable. Eventually, the concept and the design of FWRMS were developed at Debrecen University with respect to the technical and strict clinical requirements presented in Section 2. The system is designed for research investigations and prototyping, with the help of Rehabilitation Practitioners.

The rest of this article is as follows: Section 2 defines the technical and clinical requirements. Afterward, Section 3 describes the general mechanical design steps and concepts; This section includes a Section 3.1 which demonstrates the fingers mechanism design, and a Section 3.2 which illustrates and wrist with the 3D modeling. Followed by Section 4, which explains the hardware development and implementation. Afterward, Section 5 describe the software control strategy and implementation. Ultimately, Sections 6, 6.1 and 6.2 demonstrate the experimental tests, procedures, and experiential test results and discussions. Finally, Section 7 illustrates the conclusion and future works.

\section{Technical and Clinical Requirements}

From the designers' and therapists' perspective, some clinical and technical criteria should be considered when designing a mechatronics system that interacts with humans. It is essential to integrate the motor-learning standards and practice in any neurorehabilitation assistive design. Health considerations still need to be considered in the design process of the assistive-robots rehabilitation system. Since, in some cases, the fingers are flexed because of the muscular weakness of the extender. It is indeed indispensable for the recovery system to practice finger extension and reinforce the muscle function by finger flexion training [34]; hence a detailed ergonomic design is needed. At any rate, both the therapist and the patients should psychologically accept the rehabilitation robot [11]. Surly in a robotic-assisted therapy exercise, safety is critical in the recovery process. Since the therapist usually determines and schedules the rehabilitation process and sessions. The therapist is the vital factor in the recovery process; in fact, the rehabilitation robotics advancement should help the therapist (first-user) to support the patients (end-user) in the treatment period; thus, the therapist should control the force between the robot's endeffector and the extremity affected. Additionally, based on the affected limbs' functionality and mobility, the therapist must regulate the ROMs, actuators Speed, and the device's repetition times towards the patient's limbs. The designer must consider the anatomy of the targeted limbs, the number of DOFs created by these limbs, ROMs' limitations, and the forces needed to move them.

Moreover, particular concerns about the external mechanical structure, such as the exoskeleton fingertip's attachments of the rehabilitation robot that directly integrate with different patients' limbs, should be non-toxic material and serializable material. However, it would be worthwhile if they are removable and replaceable in winding up. The set-up should quickly and effortlessly fix the patient's arms without hurting them, and it can be fit for different hand sizes.

\section{Design of FWRMS}

The proposed FWRMS, shown in Figure 2a,b can be defined as a combination of grounded-exoskeleton and end-effector mechatronics system to provide a continuous passive motion for both the fingers and wrist joints. At the mechanical mechanism design phase, it is crucial when a mechanical system is designed for hand rehabilitation; three essential aspects must be taken into consideration. Consequently, the consideration of all the criteria mentioned above requires three key factors. It is (1); the number of controlled DOFs (2), the number of mechanical connections (MCs), human phalanges (3), exoskeleton mechanism structure. To accomplish one DOF for finger F/E, two DOFs for wrist F/E, R/U, and one DOF for forearm $\mathrm{P} / \mathrm{S}$, the designed mechanism for finger extension should have the facility positioned on the hand. A mechanical modeling and mechanism simulation 
method was required to understand then reduce the complexities of the mechanical and electrical structure between the fingers. The proposed system was designed and assembled using Autodesk ${ }^{\circledR}$ Inventor ${ }^{\circledR}$ Professional software (2020, Autodesk, Inc, San Rafael, CA , USA, 2020), while the 3D hand model was developed using Autodesk ${ }^{\circledR}$ Maya ${ }^{\circledR}(2020$, Autodesk, Inc San Rafael, CA , USA, 2020). Most of the designed components were printed $3 \mathrm{D}$, and each part was manufactured with the easy to use and bio-degradable polylactic acid (PLA) filament. In accordance with physiological configurations of the trainable joints (by FWRMS), both the grounded-exoskeleton, end-effector structures, and the number of degrees of freedom (DOFs) are constructed. The FWRMS is powered by one stepper motor on one side of the actuator, which provides a rotating motion transformed into a linear displacement using a mechanism of indirect feeding, which enables the finger to be displaced through the leading screw and nut transmission. The motor's other side is used to drive a rotational angular velocity into the wrist and forearm joints. Figure 2 demonstrates the 3D structure of the overall architecture and human-robot integration. The proposed prototype's overall exterior dimensions are $40 \times 25 \times 20 \mathrm{~cm}$ with a total mass (including the actuator, the driver, and all the attachments) of $9 \mathrm{~kg}$.

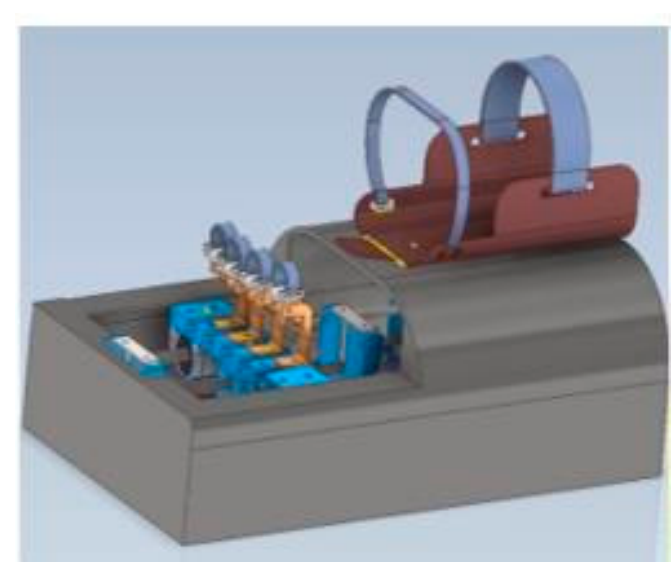

(a)

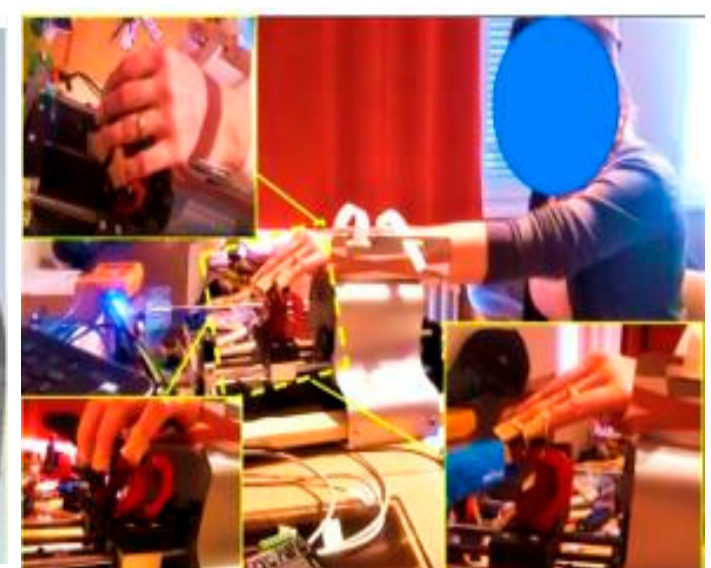

(b)

Figure 2. A general overview of the proposed FWRMS prototype, (a) 3D structure overview of the FWRMS prototype; (b) real healthy object's hand integration with the proposed system.

\subsection{Fingers Mechanism Design}

The mechanical parts of the finger's mover demonstrated in Figure 3a. Some of the fingers mechanical parts are a follow-up to recently developed [35]. From Figure 3a, we can observe the linear dynamic model of the proposed mechanical structure and transmissions mechanism, which is composed of an electrical motor holder, the base, a mechanical coupling, leading screw, nut, supporting bearings, sliders, linear motion ball bearing, a worktable. The FWRMS finger's rehabilitation mechanism design has the following characteristics: adopting an indirect feed drive with leading screw and nut mechanism. The leading screw and the motor's shaft connected through mechanical couplers. The motor's torque operates a rotational angular velocity, which generates a dynamic force between the external thread of the leading screw and the nut's internal thread; at this point, once the revolution is provided, the screw and nut threads convey the thrust. In this design, the nut is positioned then fixed at the button of the worktable. The driven nut then induces a linear displacement to the worktable. Eventually, this mechanism makes the rotational torque convert into translational velocity. 


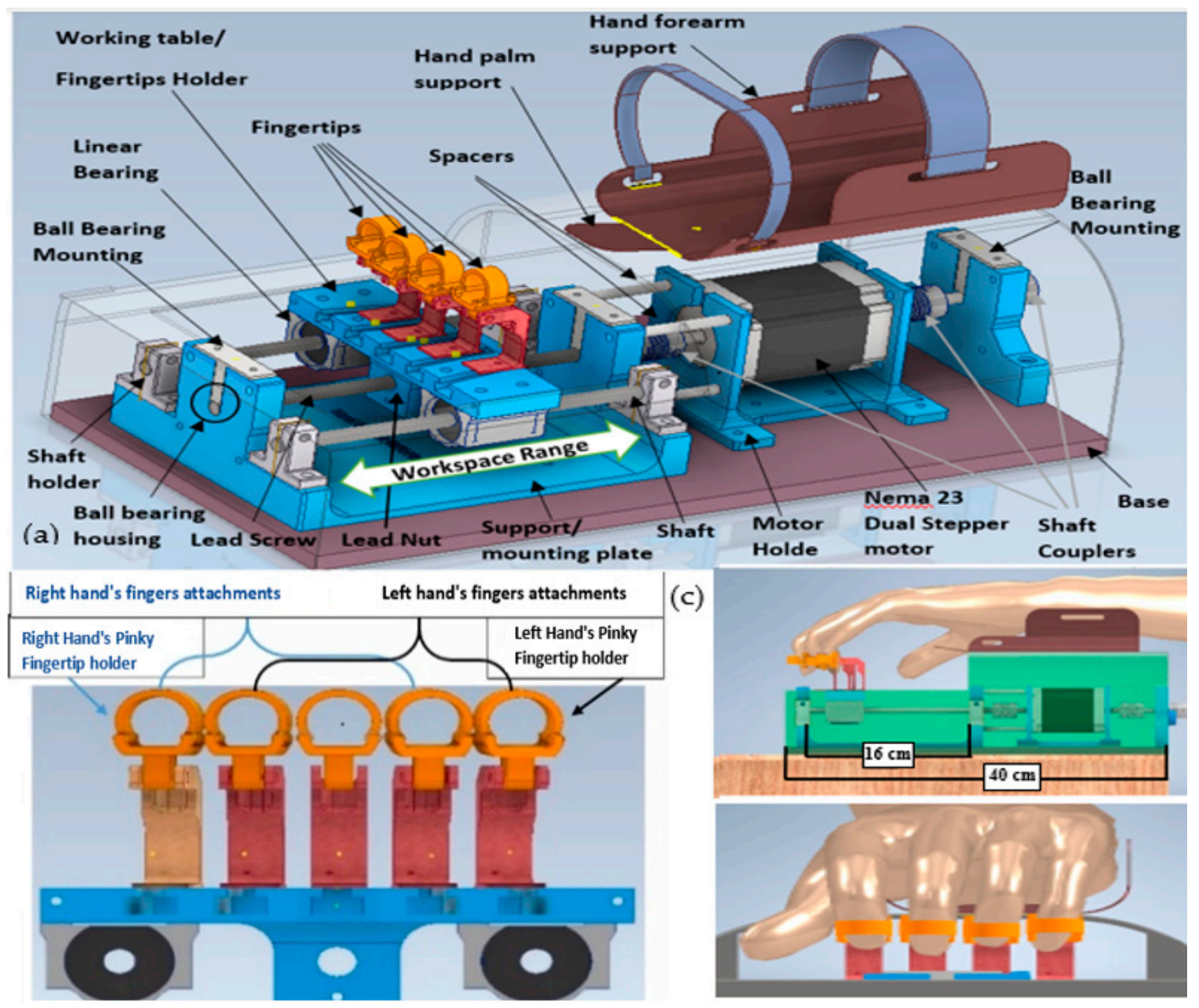

(b)

Figure 3. The grounded-exoskeleton of the fingers rehabilitation: mechanism design: (a), The Finger rehabilitation indirect feed drive screw and nut mechanism design with all parts; (b) front view of the worktable with exoskeleton fingertips design, since the fingers' anthropometric and positions of the right and the left hand, are not the same, especially the pinky finger. Therefore, we designed five adjustable fingertips holder to be suitable for either hand's pinky finger; (c), side view 3D structure model of the FWRMS device and human finger interaction; (d), Front view, 3D structure model of the human finger-robot interaction.

By taking advantage of produced linear displacement, the exoskeleton fingertips, as demonstrated in Figure 3b, were placed, and fixed on the top of the worktable, designed to be the exoskeleton fingertips holder. The same displacement will transfer to each exoskeleton fingertip. Furthermore, the exoskeleton fingertips designed to converts the driven displacement again into rotary motion, which is copying the finger's nature trajectory workspace; in other words, the exoskeleton rotation range will be limited to the patient's fingers ROM; this mechanism assists the patient to freely and neutrally move their fingers. This mechanism's advantage is that the patient places their hand (load) onto the machine, leading to fewer mechanical parts integrations; this is considered a safety and comfort feature, not the opposite, where the mechanical assemblies are placed on the patient's fingers and top palm. Moreover, the fingertip's holder is adjustable to fit different hand sizes and lengths for either right or left hand, as demonstrated in Figure 3b. Additionally, 
since the exoskeleton fingertip is the integration part between the patient's fingers and FWRMS, they are designed to remove, changeable, and more hygienic. The base limits the worktable's mechanical structure and exoskeleton fingertips to limit driven displacement with respect to the finger's workspace.

Eventually, regarding the finger's rehabilitation, the end-users arm should be fixed and appropriately fastened from the lower side of the forearm by using woven belts throughout the therapy process. The hand forearm cuff support presented in Figure 3a; ultimately, Figure $3 \mathrm{c}$, d shows the 3D structure of the proposed fingers grounded-exoskeleton design machine and end-user hand and fingertips integration.

\subsection{Wrist and Forearm Mechanism Design}

The wrist joint links the hand and the forearm together, the wrist formed by a series of eight carpal bones and a soft tissue wrapping them, basically the wrist important small joint anatomic planar structure. The wrist joint performs one DOF for wrist flexion/extension and one DOF for wrist radial/ulnar deviation [32,36]. One DOF by the forearm joint is process supination/pronation $(\mathrm{S} / \mathrm{P})$, thanks to the elbow joint [37]. FWRMS approach provides a continuous passive motion to the wrist joint movement $(F / E, R / U)$ and forearm $(\mathrm{P} / \mathrm{S})$ from the other side of a dual-sided actuator used to power these joint movements. The motor's torque causes the angular velocity to rotate with different ranges; these ROM are limited to the same functional ROM of targeted joint movement. Moreover, the motion can be started just from the zero position to ensure more safety.

Furthermore, we designed special mechanical attachments to integrate and transmit these ROM to the desired joints movement. For each targeted joint movement, the attachments are designed to handle the hand palm as fastened to it. In the preliminary set-up, the mechanical handles must be individually and physically integrated with the actuator shaft; then, they either fix or replace another handle. This solution significantly reduces the complexity of the mechanical structure's entire space and cost. In general, the 3D mechanical structure of the wrist rehabilitation for wrist F/E attachment and mechanism is illustrated in Figure 4.

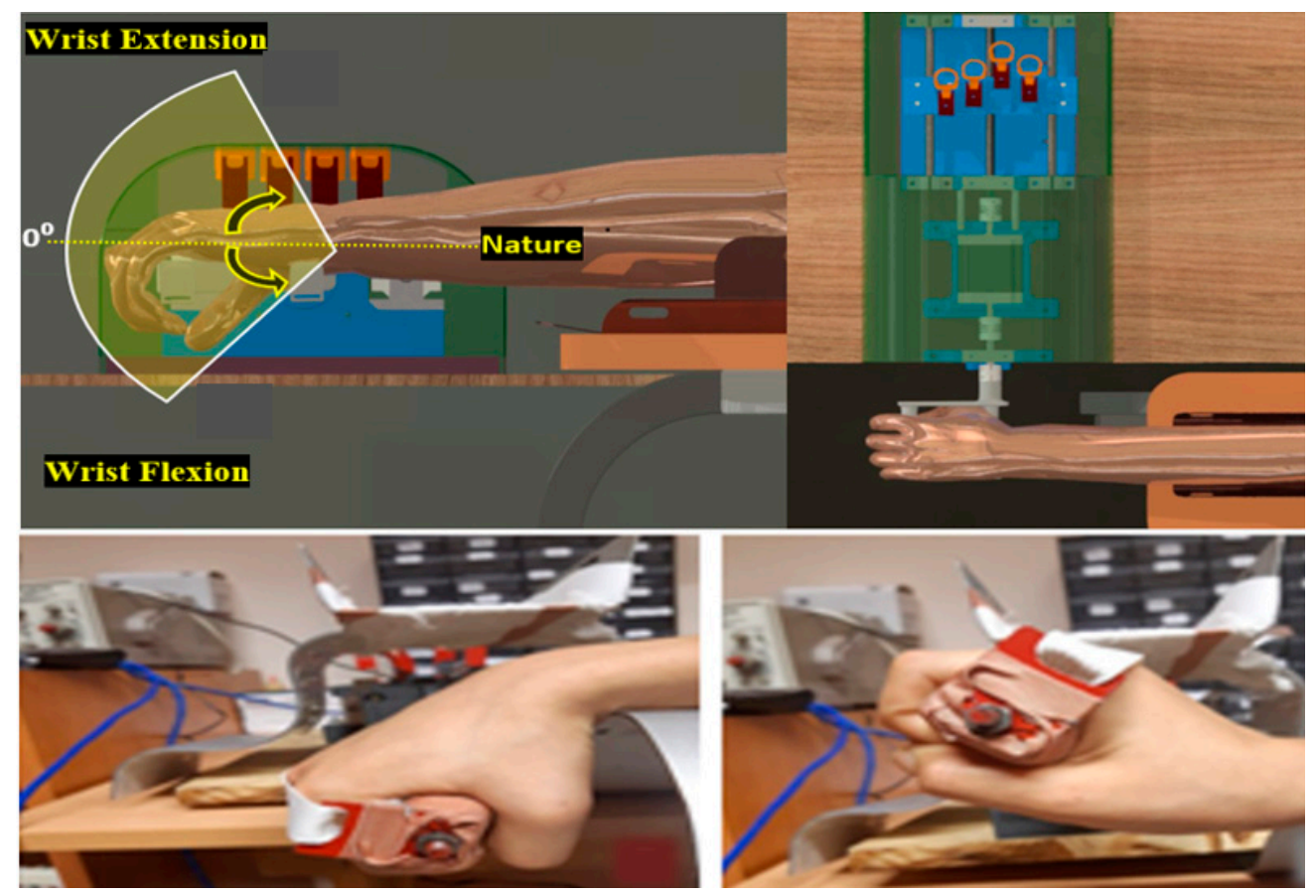

Figure 4. 3D model structure and health object integration with the proposed wrist flexion/extension (F/E) attachment mechanism. 
For the wrist R/U handles, Figure 5 demonstrated the robot-human integration and the top and side view of 3D structure and real object movement of the rehabilitation robot mechanism, while Figure 6 illustrated the forearm P/S attachment mechanism.

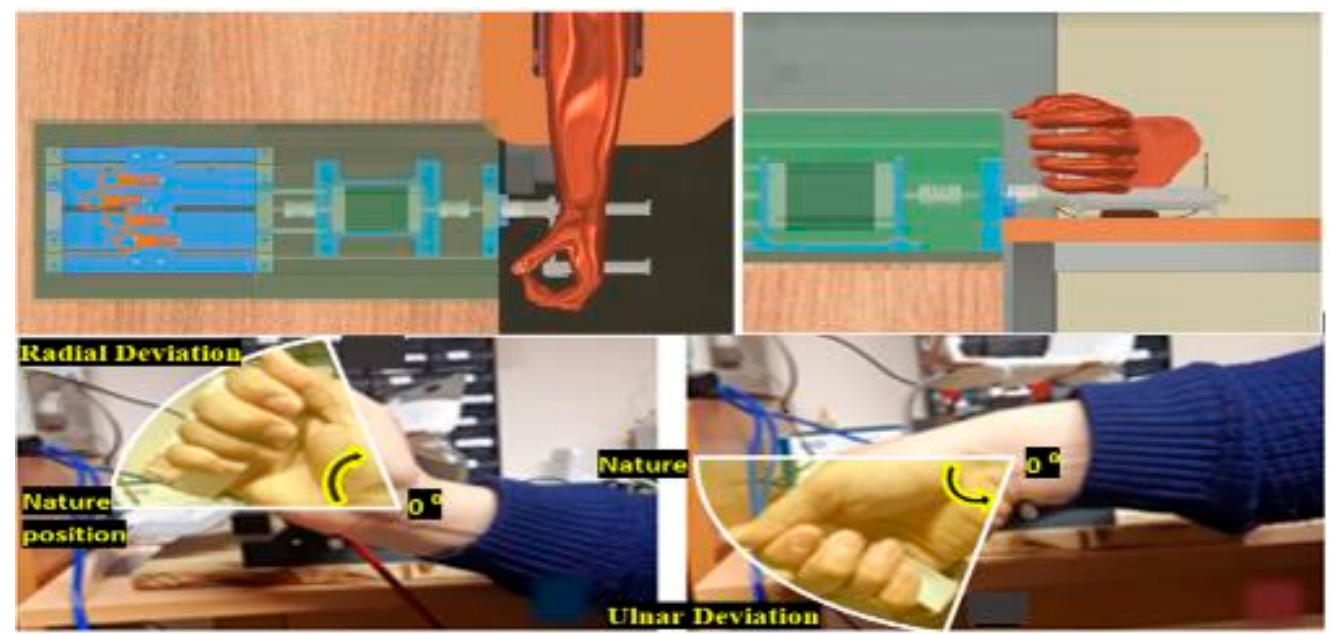

Figure 5. $3 \mathrm{D}$ model structure and health object integration with the proposed wrist radial/ulnar deviation $\mathrm{R} / \mathrm{U}$ attachment mechanism.

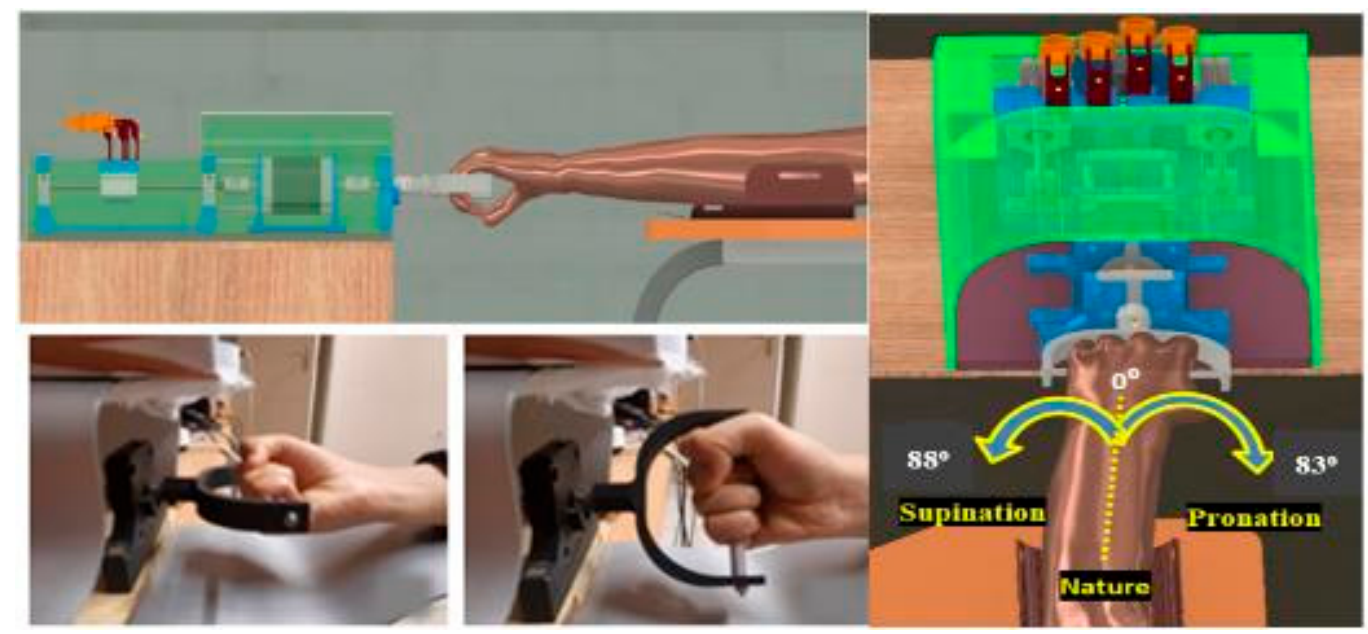

Figure 6. 3D model structure and health object integration with the proposed hand forearm supination/pronation (S/P) attachment mechanism.

Like the design of finger therapy, the forearm should be configured to the robot in the wrist rehabilitation. Firstly, the end-users must be guided to position their forearm on the mechanical forearm support then tie it using woven belts fixed onto a chair. Then fasten their palms to the desired already motioned attachments only by replaceable Velcro straps. However, to get smother therapy, the patients should sit on a seat, and the targeted joint and the device should be equal in height, then the patients should produce a grabbing capability to hold the end-effector of the proposed machine during therapy sessions.

\section{The Hardware Design and Implementation}

We designed a user-friendly, low power consumption, and portable control unit to implement the proposed system's objectives. Figure 7 illustrates the hardware composition and relationship. The electrical scheme is divided into two subsystems operated by two microcontrollers; they are connected to one other via the serial interface (UART) through a master-slave relationship as demonstrated in Figure 8c. We used a twisted cord cable with 
a baud rate of 9600 bps to connect the two subsystems; this cable is flexible; it goes between $30 \mathrm{~cm}$ to $2 \mathrm{~m}$; this feature allows the control unit holder (first-user) to move freely, without needing to be close to the patient or the machine. This interface enables the first subsystem (master), which serves as the interaction unit with the first user, to send a preprogrammed command characters to the second subsystem (slave). The first subsystem is composed of the following parts:

1. A display unit, a $16 \times 2 \mathrm{LCD}$ (Liquid Crystal Display), it is a low-cost, fundamental display module. Technically, it has 16-pin, which can display 16 characters per line; each character appeared in a $5 \times 7$ pixel matrix. Functionally, it displays the preprogrammed therapy characters; unlike other primary display devices such as seven segments, there is no limitation of displaying unique and custom characters; as a function, all the control parameters display through it.

2. Three pushbuttons with LEDs, and a buzzer, is implemented. The first pushbutton is employed to start the therapy. The second pushbutton is utilized to pause/resume the therapy execution session temporarily, and the third pushbutton deactivates the actuation unit and cancels the therapy immediately; this is important as a safety feature at the hardware level. Furthermore, whenever a pushbutton clicks, the buzzer gives a piping sound to notify and confirm the taken action.

3. An incremental rotary encoder with a center pushbutton was employed. It is efficient input hardware for mechatronics systems, where the angular position is required; they come with buttons attached. It can be clicked by pressing the knob and is recognized by the Arduino just as any other pushbutton; the advantage of using rotary encoders is that their rotation is limitless. We have used a 24-pulse mechanical, incremental rotary encoder with a pushbutton switch to scroll through software designed menus and select control parameters options.

4. The master controller, an Arduino nano based on an AT-mega328P microcontroller, owns the advantage of low cost, compact size $18 \times 35 \mathrm{~mm}$, persuasive functions, and lightweight $7 \mathrm{~g}$, which significantly reduce the size and weight of the portable control. Arduino nano consists of 8 analog input pinouts, operates by 5 VDC operating voltage, 1 KB EEPROM, 2 KB SRAM, and 32 KB flash memory. The required current per each I/O pinouts is $40 \mathrm{~mA}$. All input data and output commands of the first subsystem's pushbuttons, LEDs, buzzer, and LCD, and the incremental rotary encoder are controlled through it.

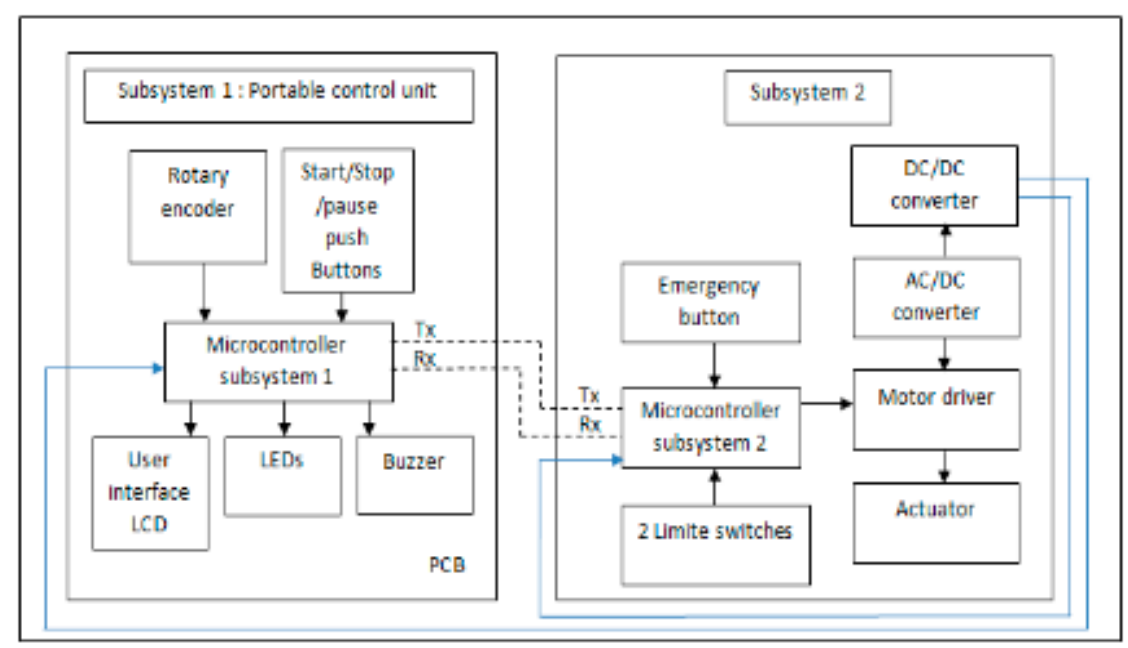

Figure 7. Electrical of design of the FWRMS Continuous Passive Motion (CPM) machine. 


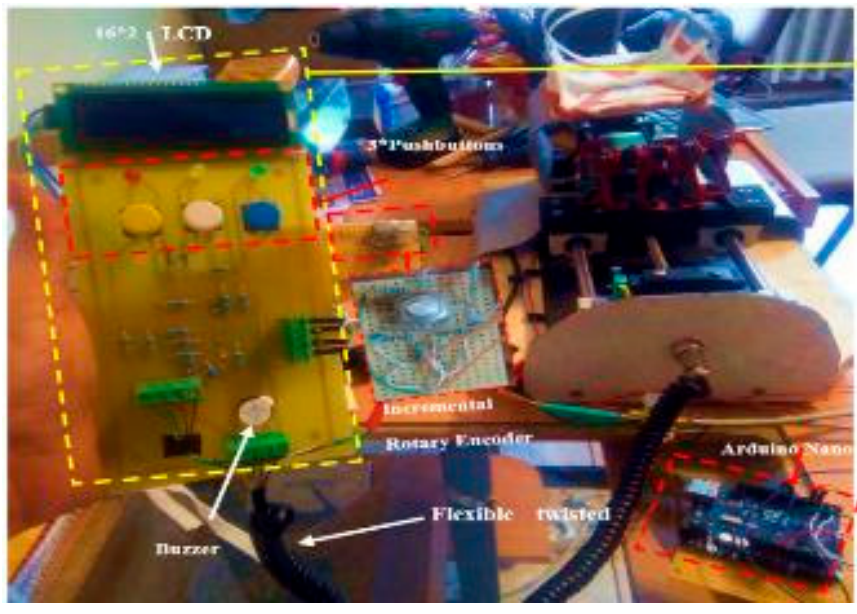

(a)

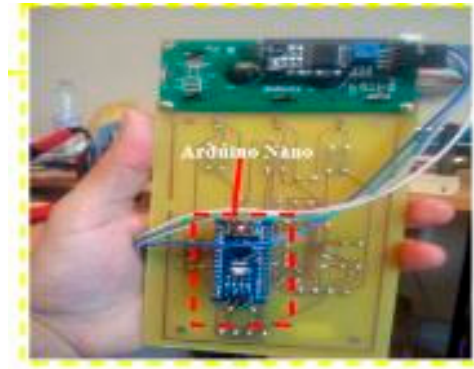

(b)

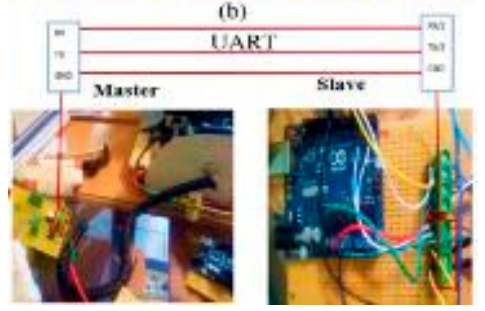

(c)

Figure 8. Hardware implementation and PCB design of the portable control unit, (a) front view of the hardware step-up; (b), back view of the portable control unit; (c) The serial communication (UART) between two microcontrollers: Arduino Nano (Master) TX pin, transmits the serial data including selected therapy control parameters to other Arduino Uno (Slave) RX pin which, once the therapy is executed then RX and TX pins of each Arduino vice versa send back.

The second subsystem (slave) receives the first subsystem's commands; it is on an Arduino Uno board based on the ATmega328 microcontroller. Technically it has six digital $\mathrm{I} / \mathrm{O}$ pins, six analog inputs, a $16 \mathrm{MHz}$ crystal oscillator, the operating voltage is $5 \mathrm{VDC}$, 1 KB EEPROM, 2 KB SRAM, 32 KB flash memory, the required current per each I/O pinouts is $20 \mathrm{~mA}$. This subsystem design to control the actuation unit. Beside the microcontroller, it essentially consists of the following parts.

1. Concerning the actuator, a hybrid bipolar dual shaft stepper motor is utilized in the actuation unit. A step motor is a brushless DC electric motor which often employed in the biomechatronics system [38]. Precise positioning control in medical devices is essential. We utilized a NEMA23 stepper motor with the configurations of; a two-phase motor with four leading wires, holding torque $1.3 \mathrm{~N} . \mathrm{m}$, rated current $4 \mathrm{~A}$, rated voltage $3.3 \mathrm{VDC}$, external dimensions $56.4 \times 56.4 \times 56 \mathrm{~mm}$, and the dual shaft dimensions are $8 \mathrm{~mm} 6.35 \mathrm{~mm}$. Figure 3 shows a 3D motor model and motor's implementation. Generally, brushless motors use non-periodic movements; it breaks a full revolution into several equivalent steps; hence the step motor does not rotate but steps, the step angle of used motor is 1.8 degrees per step.

2. Regarding single driving, A $2 \mathrm{~m} 542$ stepper driver is used to control our system's desired steps. The $2 \mathrm{~m} 542$ driver has the specifications of; supply voltage of 24 VDC, a pulse input frequency ranged from 0 to $200 \mathrm{kHz}$, micro-steps up to 25600 steps/rev, with the implementation of a robust 32-bit Digital Signal Processing (DSP) processor. The DSP acquires the control command and converts it to the operation command of the motor. As per the motor operation commands, the DSP transmits the required signals to the drive circuit. This technology considerably enhances the stepper motor's efficiency and reduces motor's vibration, with the benefits of low noise, less current, and lower heating. Moreover, this technology can accomplish smoother motion performance at low speeds by significantly minimizing variations from the desired motor speed.

3. Moreover, mechanical limit switches, as implied by their name, limit switch are electromechanical devices. Mechanical limit switches have the advantage of high accuracy and repeatability, reliable, and low power consumption devices. We implemented two limit switches to control the worktable's mechanical functional range. The switches 
were engaged in controlling the travel worktable limit, to ensure that the worktable will be within the preselected fingers $\mathrm{F} / \mathrm{E}$ displacement range.

Concerning power management of the FWRMS's machine, we employed two power converters to supply stable voltage and the required current for different hardware components. The enter system's power supply unit includes: an AC/DC converter, which takes AC 110-260v as input, and gives 24 VDC, 51-100 W power, and 4.2 A current. This 24 VDC is used to supply the stepper motor driver and the motor. Then we implemented a DC/DC converter to supply 5 VDC was needed to supply two microcontrollers, and the rest of the electronics components.

Ultimately, some tests executed on the mentioned components approve their functionality and ability to operate the proposed prototype system efficiently. Finally, the electronic component is designed and fabricated as a printed circuit board PCB. We adopted throughhole technology (THT) to prepare the final PCB through the thermal transfer method. This technology is simple and provides sustainable connectivity. It used anti-corrosion properties. After the PCB is prepared, the holes were drilled to place the electronics component then solder them as demonstrated in Figure $8 \mathrm{a}, \mathrm{b}$ which also illustrate this. The portable control unit's implementation and the external dimensions of the portable control unit are $12 \times 8 \mathrm{~cm}$ and overall weight is $300 \mathrm{~g}$.

\section{Software Control Method Implementation}

One of the software control development's crucial objectives is to obtain a userfriendly and safe control unit to carry out all the trainable joints movement. The developed software's control model was created to run as a menu, coded using the $\mathrm{C}$ programming language. A menu is one of the most straightforward ways users can navigating through and interact with devices with various features. The menu approach is used at most of our ADL devices (e.g., Smartphones, PCs, and TVs), in almost every electronic device with a screen. We initialized the needed libraries for each input and output I/O devices interface pins in the code. The incremental rotary encoder's enrollment enables the users to scroll through the menu items (control parameter options) by turning the encoder's shaft to the right or left. In contrast, the central pushbutton of the encoder is used to select the desired menu item. The developed embedded software enables the therapist to control the necessary therapy control parameters includes the ROM, speed, and repeat time generated towards the patient's limb.

The developed menu structure is summarized in Figure 9. The menu item starts with a welcoming message; the main menu contains the trainable joint's movement (therapy type). In addition, we built a sub-menu that contains therapy control parameters includes: $\mathrm{ROM} /$ Distance, speed, repeats time for each therapy type. Once the therapy control parameters are selected, the menu item waits for a start button to be pressed. The therapy session can be started simply by clicking the control unit's start button. The program runs and executes until the therapy repeat time finishes. Moreover, during the therapy execution, the developed software monitors and displays the execution repeat's numbers. The control steps implementation to start a therapy are summarized as follows.

1. A confirmation warning will emerge from the sub-menu after selecting the desired trainable joint from the main menu, asking whether or not to confirm the type of therapy chosen; this is an additional safety feature at the software level.

2. After confirming the chosen F/E range, the second step is to select the desired ROM degrees for the wrist and forearm joints or minimum and maximum displacement to flex and extend the wrist and forearm therapy fingers. FWRMS controller is programmed to provide the Wrist $\mathrm{F} / \mathrm{E}$ with controllable rotational ROMs ranged from $0^{\circ}-78^{\circ} / 0^{\circ}-68^{\circ}$, Wrist $\mathrm{R} / \mathrm{U}$ from $0^{\circ}-28^{\circ} / 0^{\circ}-38^{\circ}$, while Forearm $\mathrm{S} / \mathrm{P}$ from $0^{\circ}-88^{\circ} / 0^{\circ}-83^{\circ}$. as shown in Table 2. To achieve these degrees, we implemented a position control method for the stepper motor. The necessary steps of the position control method of the used stepper motor include: Since the used motor step angle is 1.8 degrees, which means, for each step, the motor rotates 1.8 degrees; by using a simple calculation, the 
number of steps produced by the motor that needed to achieve the desired degrees for example 45 degrees can be determined (revolution Steps for each revolution = $45 /$ step angle, $(45 / 1.8=25$ Steps for each revolution). practically, in order to achieve the desired 45 degrees, the motor driver sends 25 pulses into the step pin. Therefore, in the backend code, the developed loop has 25 iterations, so the step pin for pulse generation is adjusted on a high state and then low for each iteration. Once the 25 derived steps are executed, we add a two-second delay and then alter the rotation orientation by turning the direction pin on a low state pin, in that method we could also control the repeat numbers of the motor execution. In the developed menu items the users can select the number of the desired repeats ranged between 0-200 repeat. This method of was applied at all therapy execution control, and FWRMS took advantage of these steps to control and set the desired angular position.

3. However, for the execution method for finger $\mathrm{F} / \mathrm{E}$ is specified, the machine will look to extend the fingers to a desired maximum value of extension; until it is executed, it will look then to the desired flexion minimum value. The controller checks whether the fingers have reached those limits by tracking the stepper motor steps via the stepper driver to control the desired steps. Therefore, no position feedback sensor is required, which significantly reduces our proposed system's overall cost. However, for the finger's F/E, we have limited the derived steps numbers in the developed main menu to match the worktable's functional range. As demonstrated in in Figure 10 the displacement range is between $(0$ to $-8 \mathrm{~cm})$ for fingers flexion $(0$ to $+8 \mathrm{~cm})$ for fingers extension. These ranges of displacement are enough for the functional ranges of different fingers.

4. It is crucial to define a starting position, which is considered as a safety position. Therefore, before and after any therapy session, the exoskeleton fingertips return to their starting position (zero position). Figure 10 demonstrates the summarized block diagram of the control working flow. The actuator starts spinning until it reaches the worktable's maximum workspace physically clicks the first limit (+LS) switch. Once the +LS signals are registered, the controller disables the motor's driver's pulse signal. Eventually, that leads to stop the stepper motor, then return to the motor start spinning again in the opposite direction until the worktable reaches the other limit switch (-LS); once the - LS signal confirmed, the motor driver provides the stepper motor with the required pules until it reaches the predefined zero-position.

5. In the developed menu items, the users can adjust the therapy speed. We have implemented the speed control to drive the desired therapy speed of the desired therapy. The digital step motor driver's pulse frequency $(\mathrm{Hz})$ determines the motor speed. The pulse frequency induces the oscillatory motion. It specifies how quick to replicate a move of a certain step in a certain time. The motor pule frequency can be transformed into rpm, which indicates the revolving motion. Therefore, to regulate the stepper motor rotation speed can only be done by modifying the motor driver pule frequencies or the input pulse numbers. However, it is essential to limit the maximum motor speed on the software level; we have limited the selectable speed range for the wrist $\mathrm{F} / \mathrm{E}, \mathrm{R} / \mathrm{U}$, and Forearm $\mathrm{S} / \mathrm{P}$ between $0-10 \mathrm{rpm}$. On the other side, the required speed for fingers $\mathrm{F} / \mathrm{E}$ mechanism is higher than the other joints; because of the leading screw and nut's transmission mechanism, we have limited it to the range between 0-80 rpm, which is enough to drive smooth motion for the fingers. Table 2 summarized these technical configurations of the proposed FWRMS; it is worth to mention these specifications were selected based on the suggestions of professional therapists at the Rehabilitation Clinic, University of Debrecen. 
Table 2. Technical specifications of FWRMS device.

\begin{tabular}{ccccc}
\hline Joint & Joint ROM & FWRMS ROM & Repeat Time & Speed \\
\hline Wrist F/E & $0^{\circ}-80^{\circ} / 0^{\circ}-70^{\circ}$ & $0^{\circ}-78^{\circ} / 0^{\circ}-68^{\circ}$ & $0-200$ repeat & $0-10$ RPM \\
Wrist R/U & $0^{\circ}-30^{\circ} / 0^{\circ}-40^{\circ}$ & $0^{\circ}-28^{\circ} / 0^{\circ}-38^{\circ}$ & $0-200$ repeat & $0-10$ RPM \\
Finger F/E DIP & $0^{\circ}-0^{\circ} / 0^{\circ}-80^{\circ}$ & $0^{\circ}-0^{\circ} / 0^{\circ}-80^{\circ}$ & $0-200$ repeat & $0-80$ RPM \\
Forearm S/P & $0^{\circ}-90^{\circ} / 0^{\circ}-85^{\circ}$ & $0^{\circ}-88^{\circ} / 0^{\circ}-83^{\circ}$ & $0-200$ repeat & $0-10$ RPM \\
\hline
\end{tabular}

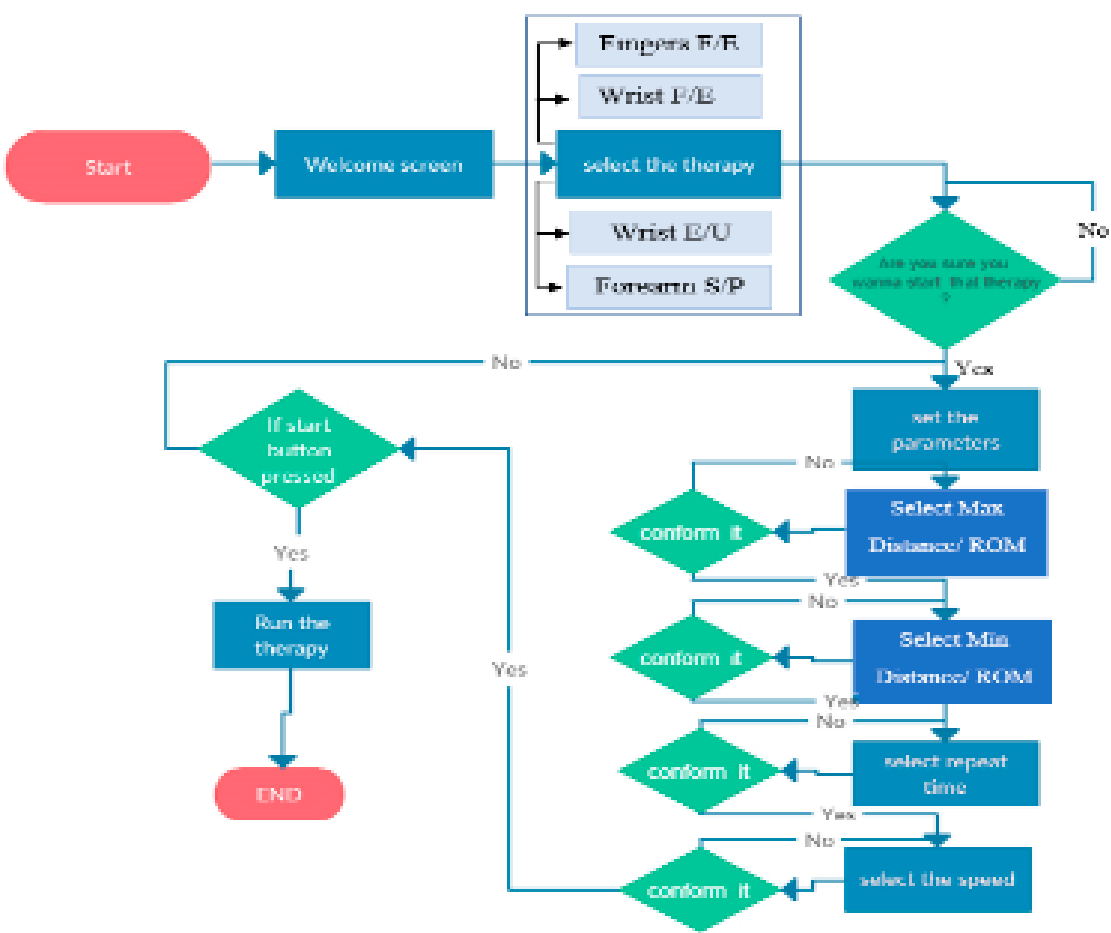

Figure 9. The software flow chart of the control strategy.

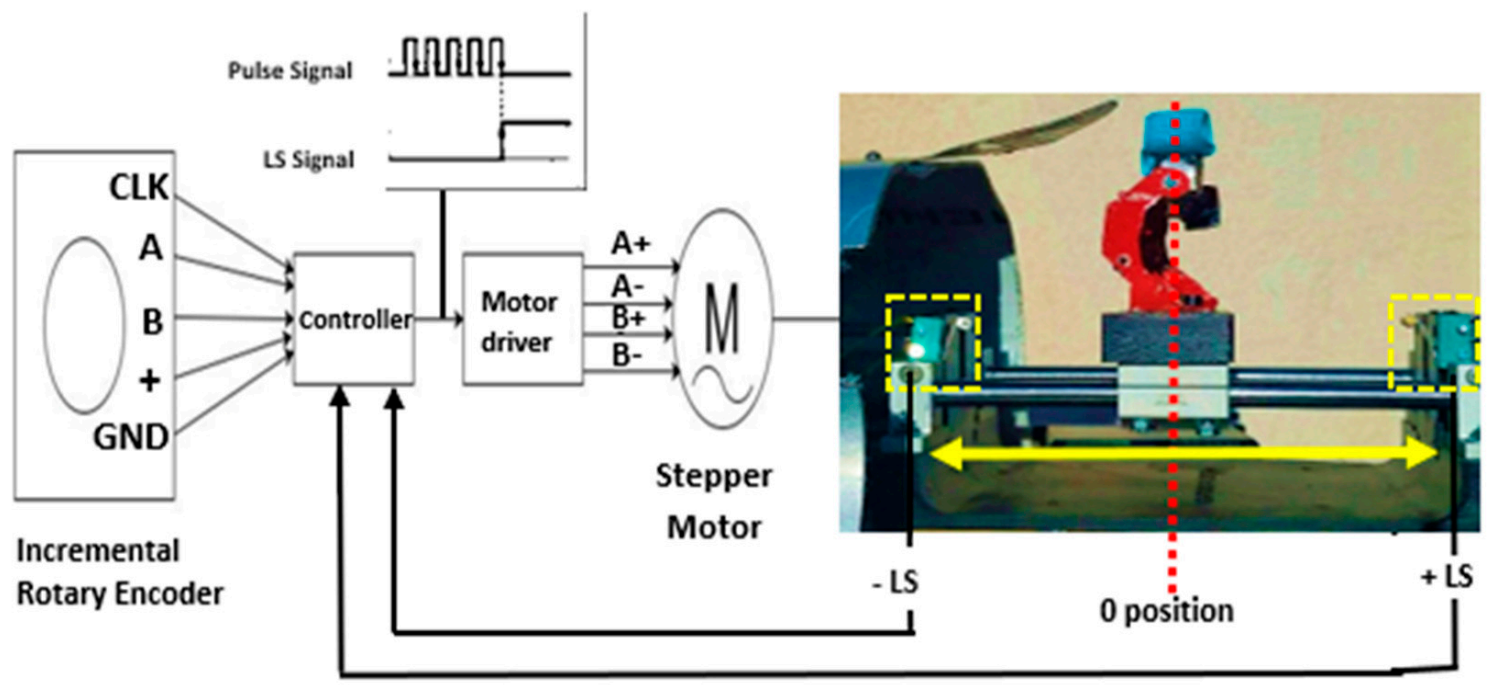

Figure 10. Block diagram of the actuation system workflow.

\section{Experimental Tests}

As stated in Section 3, FWRMS design is a desktop upper limb rehabilitation robot that adopts a grounded-exoskeleton and end-effector mechanism to drive and assist the patient's 
fingers and wrist to the desired trajectories and ROMs. In this section, we performed experimental tests to check the proposed CPM's performance and stability. Moreover, this analysis compares the experimental joint trajectories acquired during freehand movements (without FWRMS) and sets them as desired trajectories and ROMs. On the other hand, the actual trajectories, positions, and ROMs are caused by the proposed system (with FWRMS). In this way, we can obtain the workspace trajectories, ROM angles, and displacements, and the FWRMS prototype can be validated.

For that purpose, we implement the motion capture acquisition system (Kinovea ${ }^{\circledR}$ v0.9.3 [39]). Kinovea ${ }^{\circledR}$ is based on $2 \mathrm{D}$ motion analysis software. It is a reliable system that can measure the kinematic parameters. It was approved as a method to evaluate criteria related to time [40,41], used for various fields, including clinical therapeutic analysis [40-43]. For advanced analyses, objective and quantitative evidence may be given. Moreover, it is used as a diagnostic technique and an instrument for assessing the outcomes of under test intervention [44]. The quantitative and objective findings would help understand the FWRMS's openness.

\subsection{Experimental Procedure}

One participant is involved in the experimental tests; the participant was a healthy man with no noticeable neurological or mental disabilities. the participant was 30-years-old, $168 \mathrm{~cm}$ tall, and weighed $74 \mathrm{~kg}$, and we hypothesized that the right hand of the participant was the affected side. A primary configuration was carried out to test and capture the desired and the actual trajectories and then superimpose them in the finger's F/E experiment. In the first stage, the FWRMS was installed and fixed onto a table; then, the participant was guided to sit on a chair, place his right arm over the developed forearm support, and then fix it using a Velcro strap. Parallel to the participant's fingers and the FWRMS device, we fixed an HD camera in a certain position to capture the finger's movement. Initially, before linking up the participant's fingers to the developed exoskeleton fingertips; the participant performed a fingers F/E (without FWRMS); these gestures were video recorded, then temporarily, the camera recording was paused. Afterward, the participant was then instructed to place his fingertips to the top of the developed exoskeleton fingertip template and fix it with single-use injury tape plaster or small Velcro strap, as shown in Figures $2 b$ and $3 c$,d which illustrate human-robot integration of fingers $\mathrm{F} / \mathrm{E}$ experiment. Following selecting the therapy's control parameters and starting the device, as described in Section 5, the exoskeleton fingertip moved to the home position. Then the device starts moving accords the preselected F/E ROM degrees with a slow-motion used to extend the finger and flex it back. At the same time, we resume the video recording to capture the finger motion induced by FWRMS. Subsequently, the captured video data were analyzed using the Kinovea ${ }^{\circledR}$. However, since all fingers follow the same phalanx trajectories, we have decided to track only the index finger for simplicity.

For the first part of the video, in which the participant performed a finger F/E (without FWRMS), we placed a passive marker onto the finger phalange (DIP) to acquire the DIP joint natural workspace trajectory with respect to the coordinate frame to execute a Cartesian trajectory. Following the second part of the same captured video, we placed another passive tracking marker onto the actuated DIP joint driven by FWRMS. Ultimately, as a result, we obtain the desired trajectory superimposed to the actual trajectories that were induced using FWRMS, as shown in Figure 11b. Like the finger's F/E, the initial setup was applied in the case of wrist $\mathrm{F} / \mathrm{E}, \mathrm{R} / \mathrm{U}$, and forearm $\mathrm{S} / \mathrm{P}$, respectively, as briefly explained in Section 3.2. 


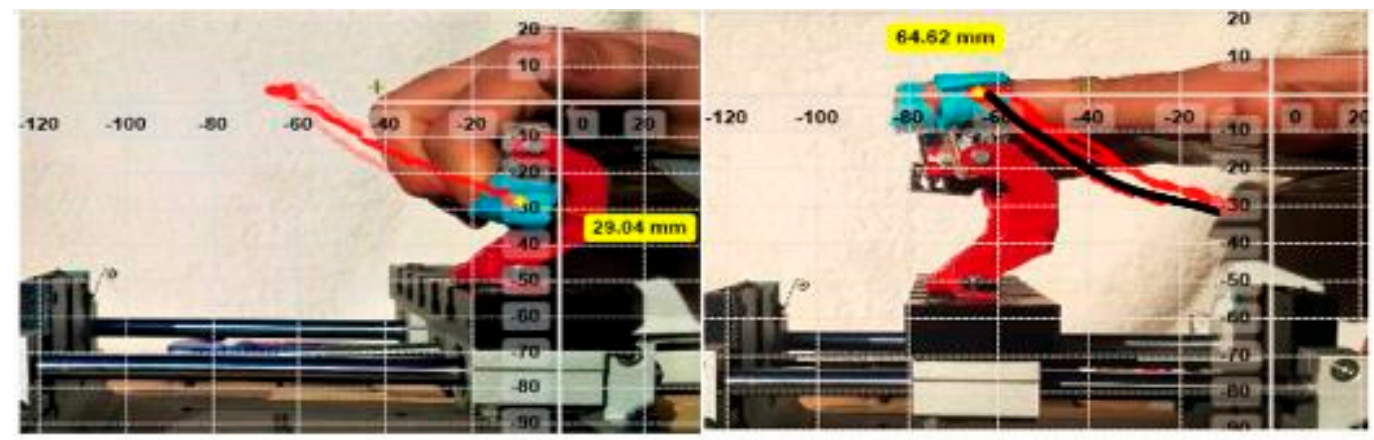

(a)

(b)

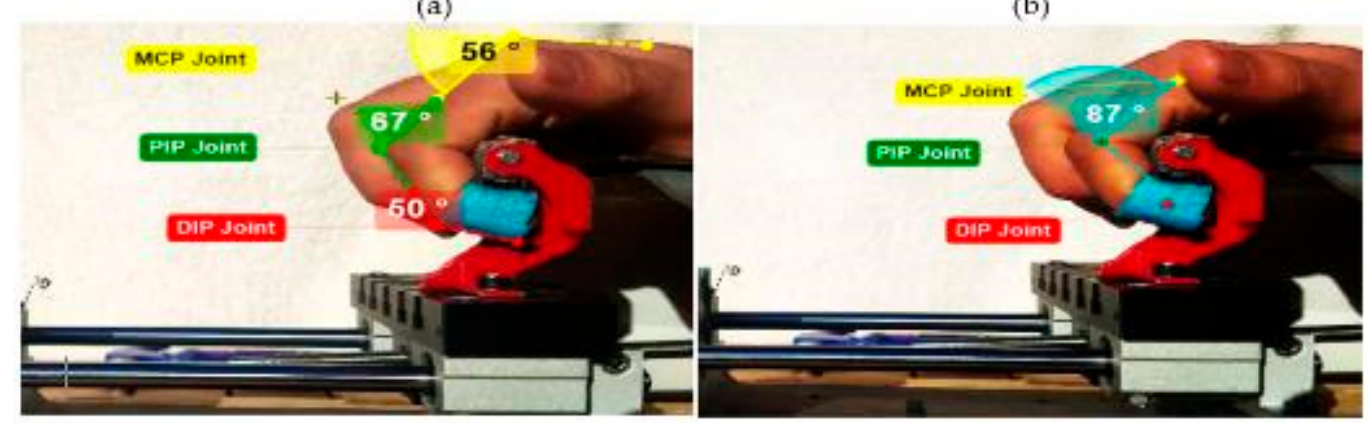

(c)

(d)

Figure 11. A real-time experimental setup of the index finger's workspace trajectories measurement: (a) Index finger fixation actual range of motion (ROM) angle, workspace trajectory, and position caused by FWRMS. (b) index finger extension actual (black curve) and desired (black curve) workspace trajectory. (c) Index finger joints (MCP, Distal Interphalangeal PIP, and Proximal Interphalangeal DIP) grasping ROM. (d) the overall grasping angle of the index finger.

\subsection{Experimental Results and Discussion}

Figure 11a,b elucidates the experimental implementation performing a continuous passive motion of the finger F/E. The solid red curve demonstrates the DIP phalanx workspace trajectory caused by FWRMS, and the solid black curve illustrates the DIP joint trajectory workspace without the FWRMS. In contrast, the yellow highlighted value presents the DIP joint's current position in the set coordinate frame. It is easy to confirm that the actuated DIP phalanx movement caused by FWRMS is within the natural functional trajectory workspace of the DIP phalanx; without FWRMS, and they are closely associated towards each other. Moreover, further analysis was carried out to study the finger joints' ROM (DIP, PIP, and MCP), driven by FWRMS to perform a finger F/E. As illustrated, Figure $11 \mathrm{c}, \mathrm{d}$, the MCP joint achieved 56 degrees, 67 degrees by PIP, and 50 degrees by DIP. These ranges are considered within the normal functional grasping range of motion of the index finger.

Besides, we have also accomplished a graphical description by analyzing the video data used for both the opening and closing phases. Figure 12a,b shows a comparative analysis between; (1) the desired DIP phalanx displacement, which plotted a solid blue curve; (2) the actual DIP phalanx displacement induced by FWRMS, which is plotted by solid orange. It is straightforward to understand that the participant performed a finger flexion and extension two times, and the plotted displacements are in both vertical and horizontal orientation, respectively. Figure 12a plots the horizontal $X$ axis, while Figure $12 b$ describes the vertical displacement in the Y-axis. 


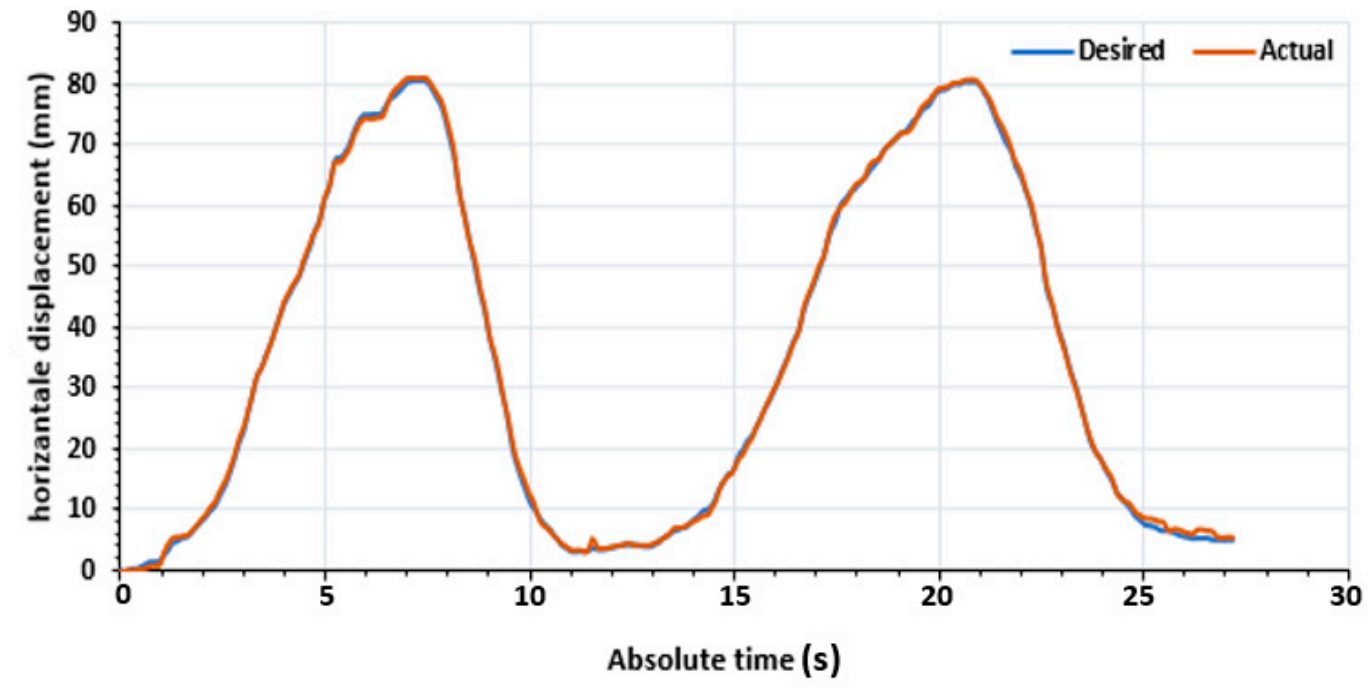

(a)

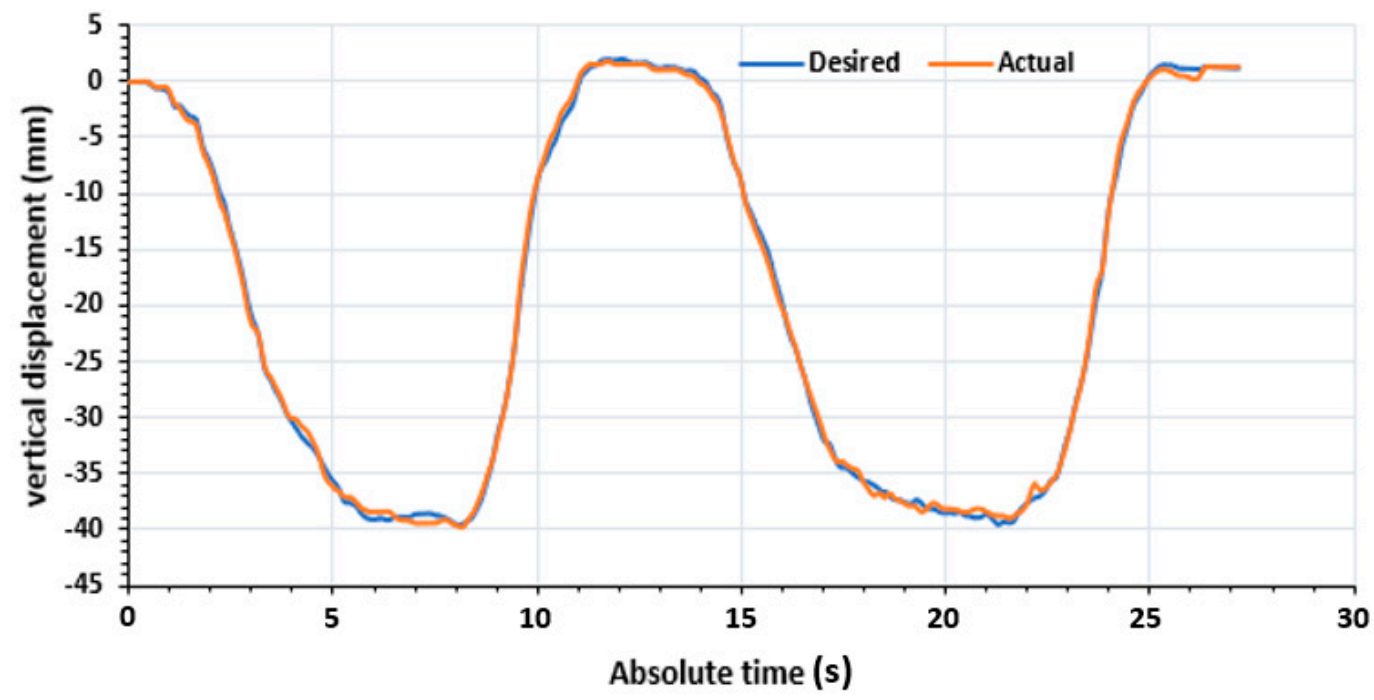

(b)

Figure 12. Continuous passive motion rehabilitation experiment of s typical finger DIP flexion and extension joint displacement;(a), horizontal displacement; (b), vertical displacement.

Moreover, we can also observe that FWRMS drives $80 \mathrm{~mm}$ of total displacement at the horizontal axis to open and close the index finger and $-39 \mathrm{~mm}$ displacement at the vertical axis; these displacements values are considered within the normal functional range of the index finger. Besides, the actual guided trajectory corresponds to the planned desired trajectory, and all the finger joints (DIP, PIP, and MCP) traveled concurrently without any movement discomfort. Accordingly, the results indicate that the motion of the finger rehabilitation design is stable. However, it can be observed that the actual and desired displacements of the DIP phalanx have a small percentage of error during the execution of the movement. It is worth noting an error percentage, about $0.874 \%$ error at the vertical axis and $1.257 \%$ error at the horizontal axis. The error rates are limited mainly by the friction between the external threads of the lead screw and the internal threads of the nut and the vibration caused by the movement. However, these small errors do not influence the CPM rehabilitation characteristics and the proposed device's performance.

Similar to the previous method, the wrist motion was studied and analyzed with and without the FWRMS device. In this experiment, we selected the desired ROM for wrist $\mathrm{F} / \mathrm{E}$ to be $\left(0^{\circ}-70^{\circ} / 0^{\circ}-60^{\circ}\right)$; these degrees were chosen to be within the wrist's normal 
ROM. Passive markers and angle measurement markers were located using the motion capture system on the targeted joint to acquire these ROM angles and trajectories; After the therapy started, the system moved smoothly according to the preselected ROM with low rpm. As can be observed in Figure 13a,b the end-user performed flexion and wrist extension gestures. From Figure 13a,b we can see; (1) the desired workspace trajectories of the wrist $\mathrm{F} / \mathrm{E}$ demonstrate black curve demonstrates the workspace trajectories (without FWRMS); (2) the actual motion of the wrist F/E workspace trajectories (with FWRMS) which indicated by the blue curve. In regards, the yellow highlighted value presents the current position of the wrist in the predefined coordinate frame. We can also observe that the two trajectories are relatively identical towards one another, and the participant has confirmed that there is no movement discomfort of the device. Furthermore, we can observe the actual (with FWRMS) ROMs of the wrist F/E are $\left(0^{\circ}-71^{\circ} / 0^{\circ}-57^{\circ}\right)$.

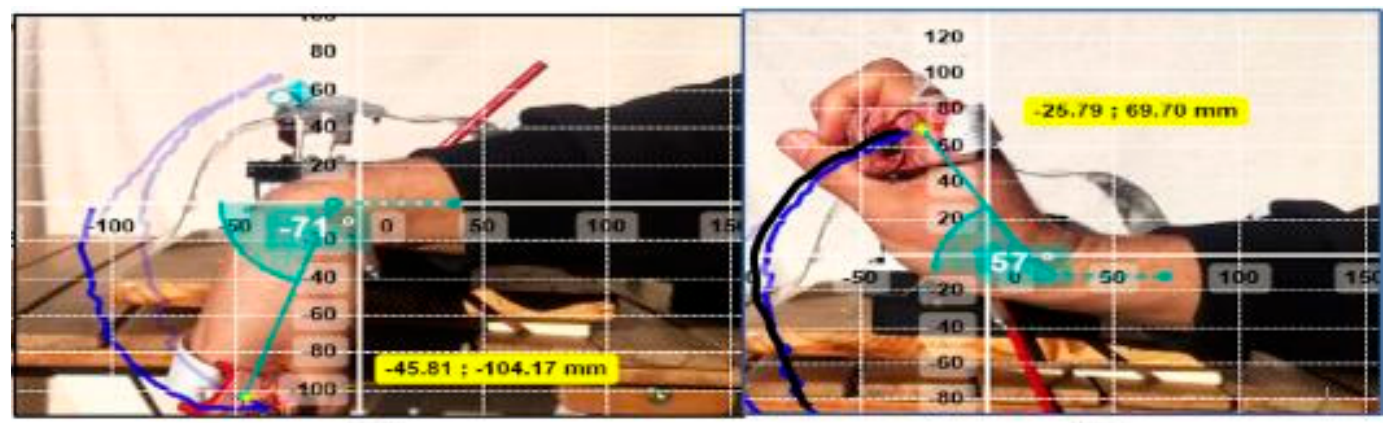

(a)

(b)

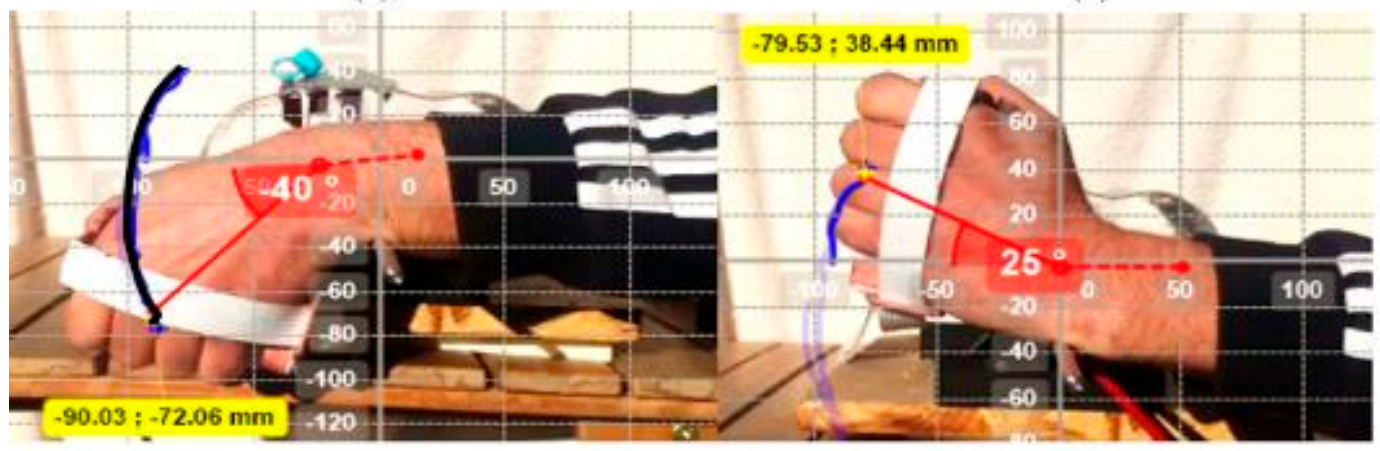

(c)

(d)

Figure 13. The real-time experiments of wrist joints workspace trajectories. (a), the actual ROM angle of the wrist fixing, the workspace trajectory, and the position caused by FWRMS. (b), actual wrist extension (blue curve) and desired (black curve) workspace trajectory and position. (c), the actual radial deviation of the wrist (blue curve) and the desired (black curve) workspace trajectory. (d), the actual wrist ulnar deviation ROM angle, workspace trajectory, and position caused by FWRMS.

We applied the same previous approach in the finger F/E; to create a graphical representation for wrist F/E ROM. Figure 14a plots a comparative analysis between the desired and actual ROMs angle of the wrist F/E during the experiment's execution. It is straightforward to observe that the end-user is performing a single F/E wrist. The vertical axis stands for the wrist's angle, while the horizontal axis stands for the execution time. The graph consists of two curves: the solid blue curve demonstrates the desired (without FWRMS) ROM angle. While the orange dash curve illustrates the actual (with FWRMS) ROM angle of the wrist F/E. It is possible to note the similarities between the two ROMs. However, from Figure 13a,b and Figure 14a we can find an observable error between the two ROMs and the workspace trajectories; the sum measured by root means square error RMSE of $1.14 \mathrm{~mm}$. 


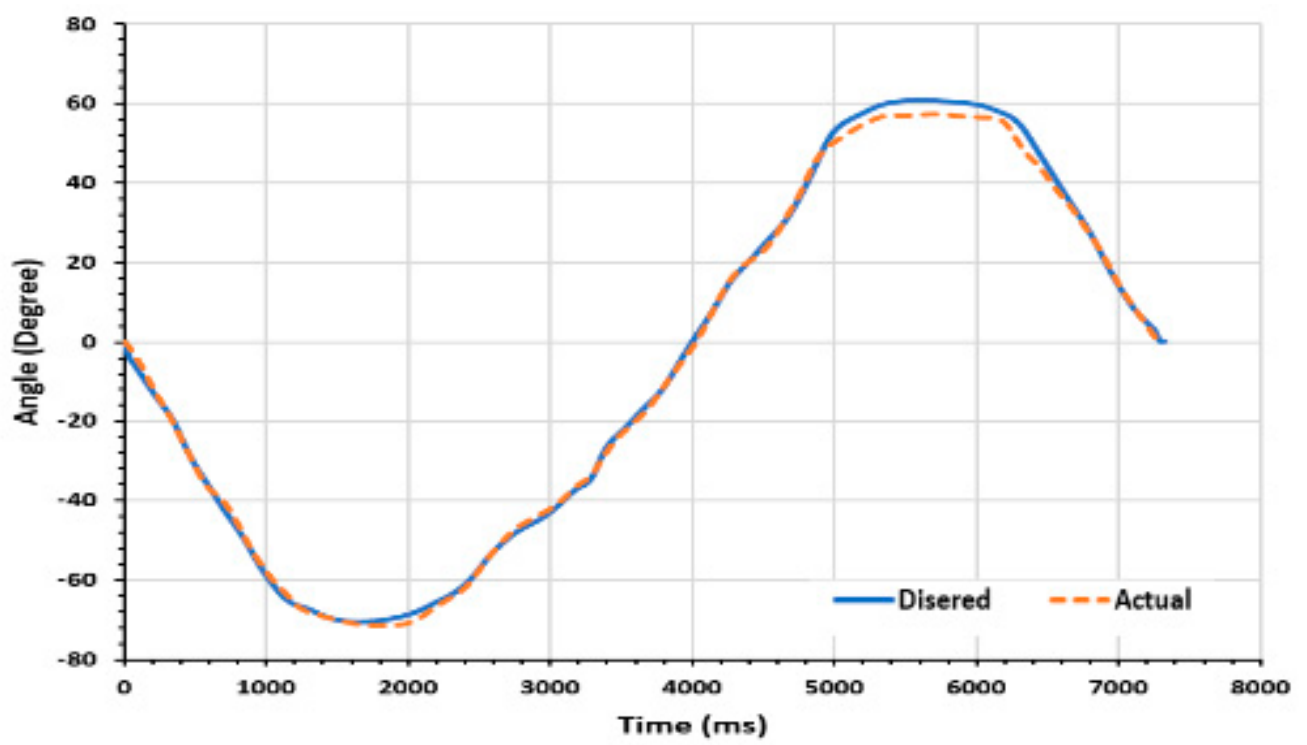

(a)

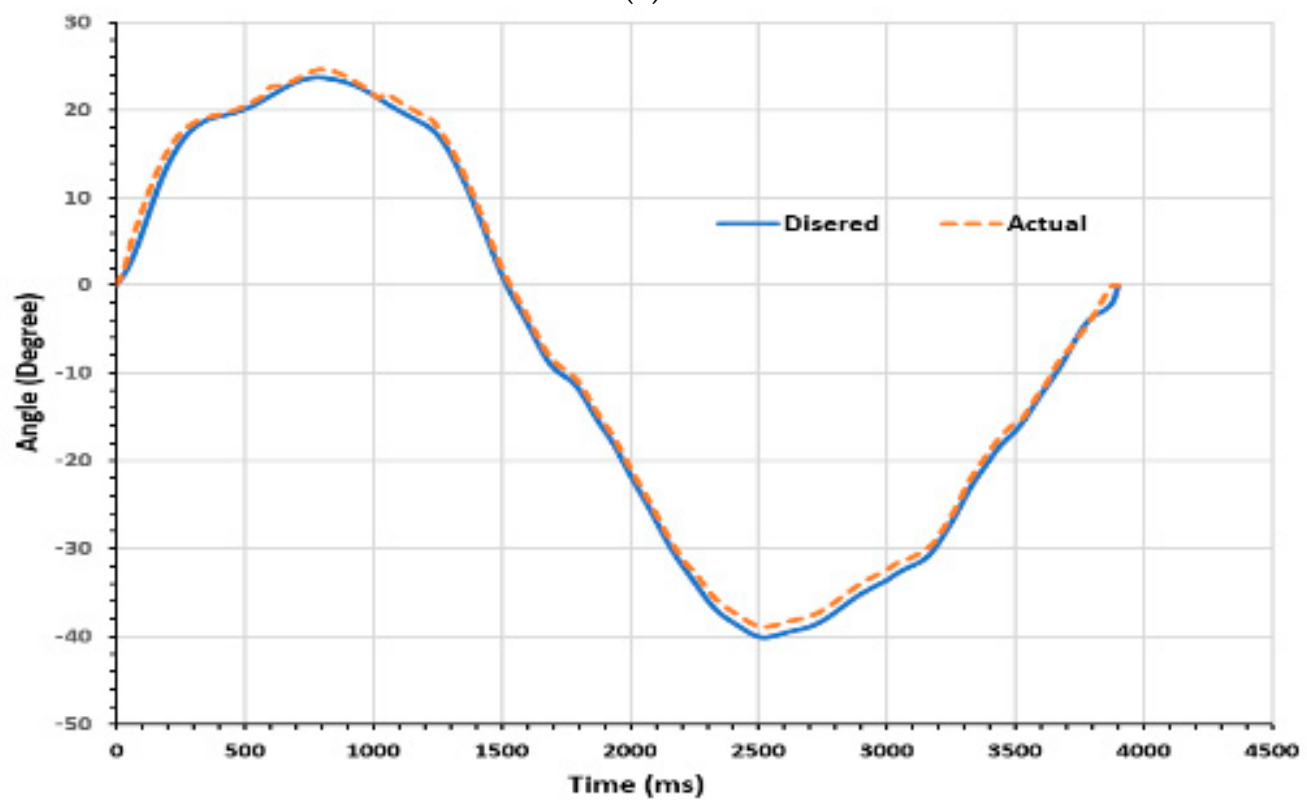

(b)

Figure 14. Continuous passive motion rehabilitation experiment of s typical; (a) wrist flexion/ extension joint; (b) wrist radial/ulnar deviation joint.

Like previous tests, we conducted an experiment to evaluate the wrist $\mathrm{R} / \mathrm{U}$ joint's functional region with and without the FWRMS machine. In this experiment, we selected the desired R/U ROM $\left(0^{\circ}-24^{\circ} / 0^{\circ}-38^{\circ}\right)$. Once the therapy was executed, the end-user performed wrist R/U motion, as shown in Figure 13c,d which indicates; (1) the black curve which describes the workspace trajectories without FWRMS; (2) the blue curve which describes the workspace trajectories induced by FWRMS. Moreover, Figure 14b plots a graphical analysis that indicates a comparison study between the desired and actual ROM angles of the wrist $\mathrm{R} / \mathrm{U}$ during the experiment's execution. The solid blue curve is plotting the desired ROM angles. While the dashed orange curve is plotting the actual ROM angles. Although comparatively both trajectories in Figure 13c and ROM angles in Figure 14b are functionally matching towards each other, but it is slightly observable that there is 
a slight error between them; it is worth nothing as an error; the sum calculated RMSE was $0.984 \mathrm{~mm}$.

Eventually, after the repeatable tests, the differences between the actual and the desired ROM were just a few millimeters for the finger's F/E and few degrees for the wrist F/E, $\mathrm{R} / \mathrm{U}$. The disparity in each measurement occurred primarily due to the mechanical frictions and vibrations caused by the mechanical coupling. However, as we have briefly explained, these differences do not affect the proposed system's training characteristics. Therefore, the results are sufficiently accurate in aspects of the stability and trajectory's alignment; the actual trajectory directly correlates to the desired trajectory, which meets the requirements of continuous passive motion training configurations.

\section{Conclusions and Future Work}

This article addressed the concept and development of a cost-effective CPM mechatronics rehabilitation device targeting the four fingers and the wrist. The proposed system is equipped with a single actuator to execute four crucial movements: finger $\mathrm{F} / \mathrm{E}$, wrist $\mathrm{F} / \mathrm{E}$, wrist E/U, and hand forearm S/P. The proposed device mechanism is based on a combination of end-effector and ground-exoskeleton mechanism. For the finger $\mathrm{F} / \mathrm{E}$ transmission mechanism, we adopted the indirect feed drive mechanism to suit typical fingers' motions. On the other side, the wrist and forearm are based on one mechanism, but separate attachments are used for each therapy. Unlike the related work in the literature $[13,14,21,25,26,28]$, the proposed system's overall structure does not load the hand with a heavy and complex mechanical structure. Additionally, owning a portable embedded control implementation enables the therapist to set the therapy control parameters conveniently. The experiential tests were conducted to evaluate and validate the device. The results of the tests indicate that the proposed system performed a continuous passive motion according to the set control parameters and the planned range of motions with negligent errors. The system was designed concerning the requirements of the clinical standards at the University of Debrecen, rehabilitation department. The cumulative cost of the device developed is estimated at approximately 300 USD. This includes the cost for all parts required to make the system, the stepper motor, the motor driver, the mechanical mechanism of the drive system, and the other electronic equipment, also including the 3D printer filament, as it is estimated to be around 500-650 g, depending on the size of each orthosis.

In future work, as this paper presented the first prototype, some future developments. Some optimizations will be considered in the mechanical mechanism and design; besides adding force feedback sensing, virtual reality games can also enhance motor recovery effectively by motivating the patients for therapy sessions.

Author Contributions: H.A. conducted research, established the methodology, designs, and participated in the writing of the paper; G.H. did the formal analysis and review of the paper. All authors have read and agreed to the published version of the manuscript.

Funding: This research received no external funding.

Institutional Review Board Statement: Not applicable.

Informed Consent Statement: Not applicable.

Data Availability Statement: The data presented in this study are available on request from the corresponding author.

Acknowledgments: The authors would like to thank confidential reviewers and the editor for their helpful comments and suggestions.

Conflicts of Interest: The authors declare no conflict of interest. 


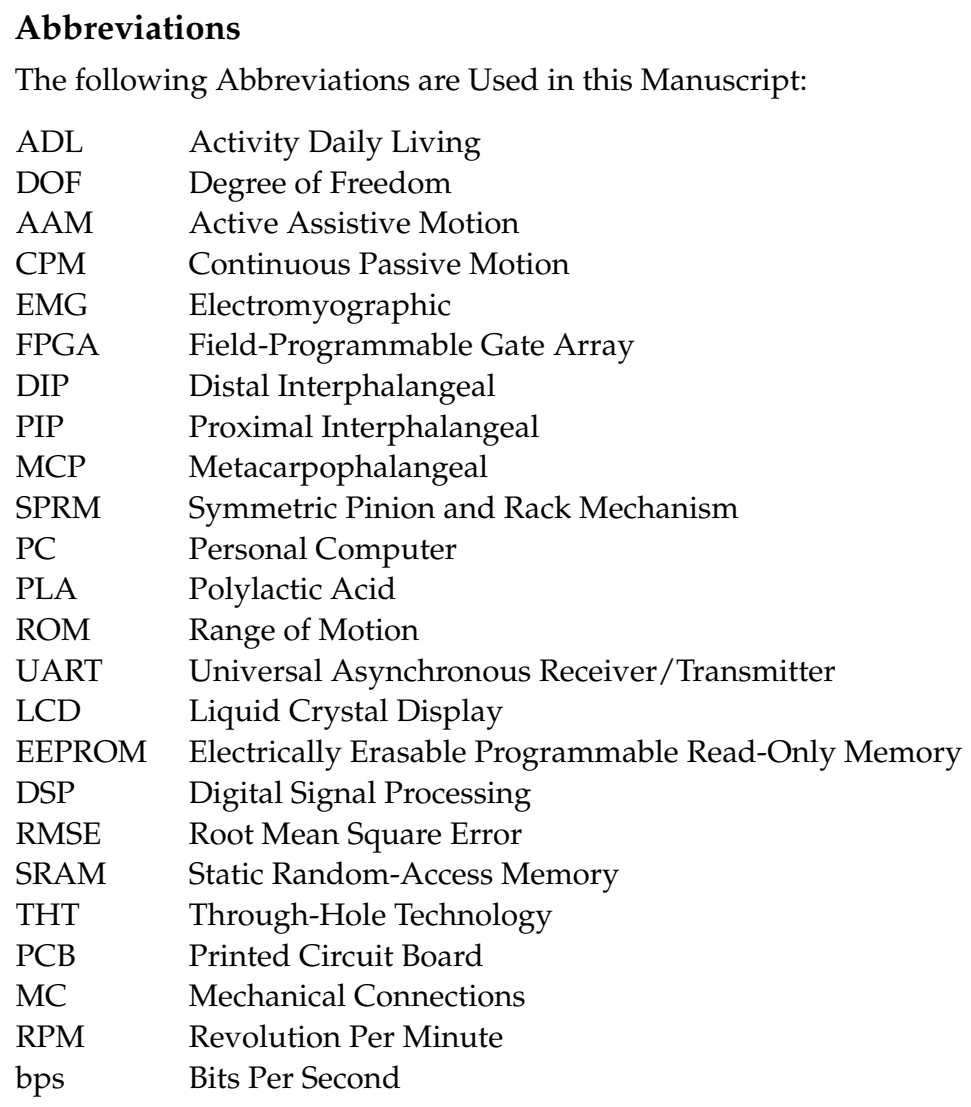

\section{References}

1. World Health Organization. Global Health Estimates; World Health Organization: Geneva, Switzerland, 2012. Available online: http://www.who.int/healthinfo/global_burden_disease/en/ (accessed on 6 December 2020).

2. World Health Organisation. STEPwise Approach to Stroke Surveillance. 2011. Available online: http://www.who.int/chp/ steps/stroke/en/index.html (accessed on 6 December 2020).

3. Harwin, W.S.; Patton, J.L.; Edgerton, V.R. Challenges and Opportunities for Robot-Mediated Neurorehabilitation. Proc. IEEE 2006, 94, 1717-1726. [CrossRef]

4. Bos, R.A.; Haarman, C.J.W.; Stortelder, T.; Nizamis, K.; Herder, J.L.; Stienen, A.H.A.; Plettenburg, D.H. A structured overview of trends and technologies used in dynamic hand orthoses. J. Neuroeng. Rehabil. 2016, 13. [CrossRef] [PubMed]

5. Ueki, S.; Kawasaki, H.; Ito, S.; Nishimoto, Y.; Abe, M.; Aoki, T.; Ishigure, Y.; Ojika, T.; Mouri, T. Development of a Hand-Assist Robot with Multi-Degrees-of-Freedom for Rehabilitation Therapy. IEEE ASME Trans. Mechatron. 2012, 17, 136-146. [CrossRef]

6. Wyndaele, J.J. Color atlas of human anatomy. Spinal Cord 1995, 47, 838. [CrossRef]

7. NHS Choices Symptoms Stroke. Available online: https://www.nhs.uk/conditions/stroke/symptoms/ (accessed on 24 October 2020).

8. Chu, C.-Y.; Patterson, R.M. Soft robotic devices for hand rehabilitation and assistance: A narrative review. J. Neuroeng. Rehabil. 2018, 15. [CrossRef]

9. Chen, B.; Zi, B.; Wang, Z.; Qin, L.; Liao, W.-H. Knee exoskeletons for gait rehabilitation and human performance augmentation: A state-of-the-art. Mech. Mach. Theory 2019, 134, 499-511. [CrossRef]

10. Maciejasz, P.; Eschweiler, J.; Gerlach-Hahn, K.; Jansen-Troy, A.; Leonhardt, S. A survey on robotic devices for upper limb rehabilitation. J. Neuroeng. Rehabil. 2014, 11, 3. [CrossRef]

11. Riener, R.; Nef, T.; Colombo, G. Robot-aided neurorehabilitation of the upper extremities. Med. Biol. Eng. Comput. 2005, 43, 2-10. [CrossRef]

12. Marchal-Crespo, L.; Reinkensmeyer, D.J. Review of control strategies for robotic movement training after neurologic injury. J. Neuroeng. Rehabil. 2009, 6. [CrossRef]

13. Kawasaki, H.; Ito, S.; Ishigure, Y.; Nishimoto, Y.; Aoki, T.; Mouri, T.; Sakaeda, H.; Abe, M. Development of a Hand Motion Assist Robot for Rehabilitation Therapy by Patient Self-Motion Control. In Proceedings of the 2007 IEEE 10th International Conference on Rehabilitation Robotics, Noordwijk, The Netherlands, 13-15 June 2007. [CrossRef]

14. Balasubramanian, S.; Wei, R.; Perez, M.; Shepard, B.; Koeneman, E.; Koeneman, J.; He, J. RUPERT: An exoskeleton robot for assisting rehabilitation of arm functions. In Proceedings of the 2008 Virtual Rehabilitation, Vancouver, BC, Canada, 25-27 August 2008. [CrossRef]

15. Lambercy, O.; Dovat, L.; Gassert, R.; Burdet, E.; Teo, C.L.; Milner, T. A Haptic Knob for Rehabilitation of Hand Function. IEEE Trans. Neural Syst. Rehabil. Eng. 2007, 15, 356-366. [CrossRef] [PubMed] 
16. Palsbo, S.E.; Hood-Szivek, P. Effect of Robotic-Assisted Three-Dimensional Repetitive Motion to Improve Hand Motor Function and Control in Children with Handwriting Deficits: A Nonrandomized Phase 2 Device Trial. Am. J. Occup. Ther. 2012, 66, 682-690. [CrossRef] [PubMed]

17. AbdulKareem, A.H.; Adila, A.S.; Husi, G. Recent trends in robotic systems for upper-limb stroke recovery: A low-cost hand and wrist rehabilitation device. In Proceedings of the 2018 2nd International Symposium on Small-scale Intelligent Manufacturing Systems (SIMS), Cavan, Ireland, 16-18 April 2018. [CrossRef]

18. Ho, T.-Y.; Chen, Y.-J.; Chen, P.-H. The design and implementation of a motor drive for foot rehabilitation. Comput. Electr. Eng. 2016, 56, 795-806. [CrossRef]

19. The Amadeo®System, Tyromotion. Available online: http://www.tyromotion.com/en/products/amadeo/ (accessed on 6 December 2020).

20. Patterson Companies, Inc._-Home. Available online: http://www.sammonspreston.com/app.aspx?cmd=get_product\&id=91378 (accessed on 6 December 2020).

21. Koeneman, E.J.; Schultz, R.S.; Wolf, S.L.; Herring, D.E.; Koeneman, J.B. A pneumatic muscle hand therapy device. In Proceedings of the 26th Annual International Conference of the IEEE Engineering in Medicine and Biology Society, San Francisco, CA, USA, 1-5 September 2004. [CrossRef]

22. Nef, T.; Guidali, M.; Klamroth-Marganska, V.; Riener, R. ARMin-Exoskeleton Robot for Stroke Rehabilitation. IFMBE Proc. 2009, 127-130. [CrossRef]

23. Sanchez, R.; Reinkensmeyer, D.; Shah, P.; Liu, J.; Rao, S.; Smith, R.; Cramer, S.; Rahman, T.; Bobrow, J. Monitoring functional arm movement for home-based therapy after stroke. In Proceedings of the 26th Annual International Conference of the IEEE Engineering in Medicine and Biology Society, San Francisco, CA, USA, 1-5 September 2004. [CrossRef]

24. Hesse, S.; Schulte-Tigges, G.; Konrad, M.; Bardeleben, A.; Werner, C. Robot-assisted arm trainer for the passive and active practice of bilateral forearm and wrist movements in hemiparetic subjects11An organization with which 1 or more of the authors is associated has received or will receive financial benefits from a commercial party having a direct financial interest in the results of the research supporting this article. Arch. Phys. Med. Rehabil. 2003, 84, 915-920. [CrossRef]

25. Cordo, P.; Lutsep, H.; Cordo, L.; Wright, W.G.; Cacciatore, T.; Skoss, R. Assisted Movement with Enhanced Sensation (AMES): Coupling Motor and Sensory to Remediate Motor Deficits in Chronic Stroke Patients. Neurorehabilit. Neural Repair 2008, 23, 67-77. [CrossRef]

26. Takahashi, C.D.; Der-Yeghiaian, L.; Le, V.; Motiwala, R.R.; Cramer, S.C. Robot-based hand motor therapy after stroke. Brain 2008, 131, 425-437. [CrossRef]

27. Hasegawa, Y.; Mikami, Y.; Watanabe, K.; Sankai, Y. Five-fingered assistive hand with mechanical compliance of human finger. In Proceedings of the 2008 IEEE International Conference on Robotics and Automation, Pasadena, CA, USA, 19-23 May 2008. [CrossRef]

28. Zhang, L.; Guo, S.; Sun, Q. Development and Assist-As-Needed Control of an End-Effector Upper Limb Rehabilitation Robot. Appl. Sci. 2020, 10, 6684. [CrossRef]

29. da Silva, L.D.L.; Pereira, T.F.; Leithardt, V.R.Q.; Seman, L.O.; Zeferino, C.A. Hybrid Impedance-Admittance Control for Upper Limb Exoskeleton Using Electromyography. Appl. Sci. 2020, 10, 7146. [CrossRef]

30. Zhang, F.; Lin, L.; Yang, L.; Fu, Y. Design of an Active and Passive Control System of Hand Exoskeleton for Rehabilitation. Appl. Sci. 2019, 9, 2291. [CrossRef]

31. Zhang, L.; Li, J.; Cui, Y.; Dong, M.; Fang, B.; Zhang, P. Design and performance analysis of a parallel wrist rehabilitation robot (PWRR). Robot. Auton. Syst. 2020, 125, 103390. [CrossRef]

32. Pang, Z.; Wang, T.; Wang, Z.; Yu, J.; Sun, Z.; Liu, S. Design and Analysis of a Wearable Upper Limb Rehabilitation Robot with Characteristics of Tension Mechanism. Appl. Sci. 2020, 10, 2101. [CrossRef]

33. Wang, D.; Wang, Y.; Zi, B.; Cao, Z.; Ding, H. Development of an active and passive finger rehabilitation robot using pneumatic muscle and magnetorheological damper. Mech. Mach. Theory 2020, 147, 103762. [CrossRef]

34. Fischer, H.C.; Stubblefield, K.; Kline, T.; Luo, X.; Kenyon, R.V.; Kamper, D.G. Hand Rehabilitation Following Stroke: A Pilot Study of Assisted Finger Extension Training in a Virtual Environment. Top. Stroke Rehabil. 2007, 14, 1-12. [CrossRef] [PubMed]

35. Almusawi, H.; Afghan, S.A.; Géza, H. Designing the Mechanical Parts of a Low-Cost Hand Rehabilitation CPM Device for Stroke Patients. Innov. Eng. Entrep. 2018, 60-66. [CrossRef]

36. Andrews, J.G.; Youm, Y. A biomechanical investigation of wrist kinematics. J. Biomech. 1979, 12, 83-93. [CrossRef]

37. Gull, M.A.; Bai, S.; Bak, T. A Review on Design of Upper Limb Exoskeletons. Robotics 2020, 9, 16. [CrossRef]

38. Ragazzo, F. Review on Upper Limb Continuous Passive Motion Devices. MATEC Web Conf. 2016, 53, 01062. [CrossRef]

39. Charmant, J. Kinovea 0.9.3, Computer Software 2020. Available online: https:/ / www.kinovea.org/ (accessed on 6 December 2020).

40. Puig-Diví, A.; Escalona-Marfil, C.; Padullés-Riu, J.M.; Busquets, A.; Padullés-Chando, X.; Marcos-Ruiz, D. Validity and reliability of the Kinovea program in obtaining angles and distances using coordinates in 4 perspectives. PLoS ONE 2019, 14, e0216448. [CrossRef]

41. Moral-Muñoz, J.A.; Esteban-Moreno, B.; Arroyo-Morales, M.; Cobo, M.J.; Herrera-Viedma, E. Agreement Between Face-toFace and Free Software Video Analysis for Assessing Hamstring Flexibility in Adolescents. J. Strength Cond. Res. 2015, 29, 2661-2665. [CrossRef] 
42. Guzmán-Valdivia, C.H.; Blanco-Ortega, A.; Oliver-Salazar, M.A.; Carrera-Escobedo, J.L. Therapeutic motion analysis of lower limbs using Kinovea. Int. J. Soft Comput. Eng. 2013, 3, 2231-2307.

43. Youssef, A.R. Photogrammetric Quantification of Forward Head Posture is Side Dependent in Healthy Participants and Patients with Mechanical Neck Pain. Int. J. Physiother. 2016, 3. [CrossRef]

44. Fernández-González, P.; Koutsou, A.; Cuesta-Gómez, A.; Carratalá-Tejada, M.; Miangolarra-Page, J.C.; Molina-Rueda, F. Reliability of Kinovea ${ }^{\circledR}$ Software and Agreement with a Three-Dimensional Motion System for Gait Analysis in Healthy Subjects. Sensors 2020, 20, 3154. [CrossRef] [PubMed] 